University of Rhode Island

DigitalCommons@URI

Open Access Master's Theses

1993

\title{
The Transtheoretical Model and Exercise Behavior: A Comparison of Five Staging Methods
}

Gabrielle Richards Reed

University of Rhode Island

Follow this and additional works at: https://digitalcommons.uri.edu/theses

\section{Recommended Citation}

Richards Reed, Gabrielle, "The Transtheoretical Model and Exercise Behavior: A Comparison of Five Staging Methods" (1993). Open Access Master's Theses. Paper 1332.

https://digitalcommons.uri.edu/theses/1332

This Thesis is brought to you for free and open access by DigitalCommons@URI. It has been accepted for inclusion in Open Access Master's Theses by an authorized administrator of DigitalCommons@URI. For more information, please contact digitalcommons-group@uri.edu. 
THE TRANSTHEORETICAL MODEL AND EXERCISE BEHAVIOR:

A COMPARISON OF FIVE STAGING METHODS

BY

GABRIELLE RICHARDS REED

A THESIS SUBMITTED IN PARTIAL FULFILLMENT OF THE REQUIREMENTS FOR THE DEGREE OF MASTERS OF ARTS

IN PSYCHOLOGY 


\section{MASTER OF ARTS THESIS \\ OF}

GABRIELLE RICHARDS REED

\section{APPROVED :}

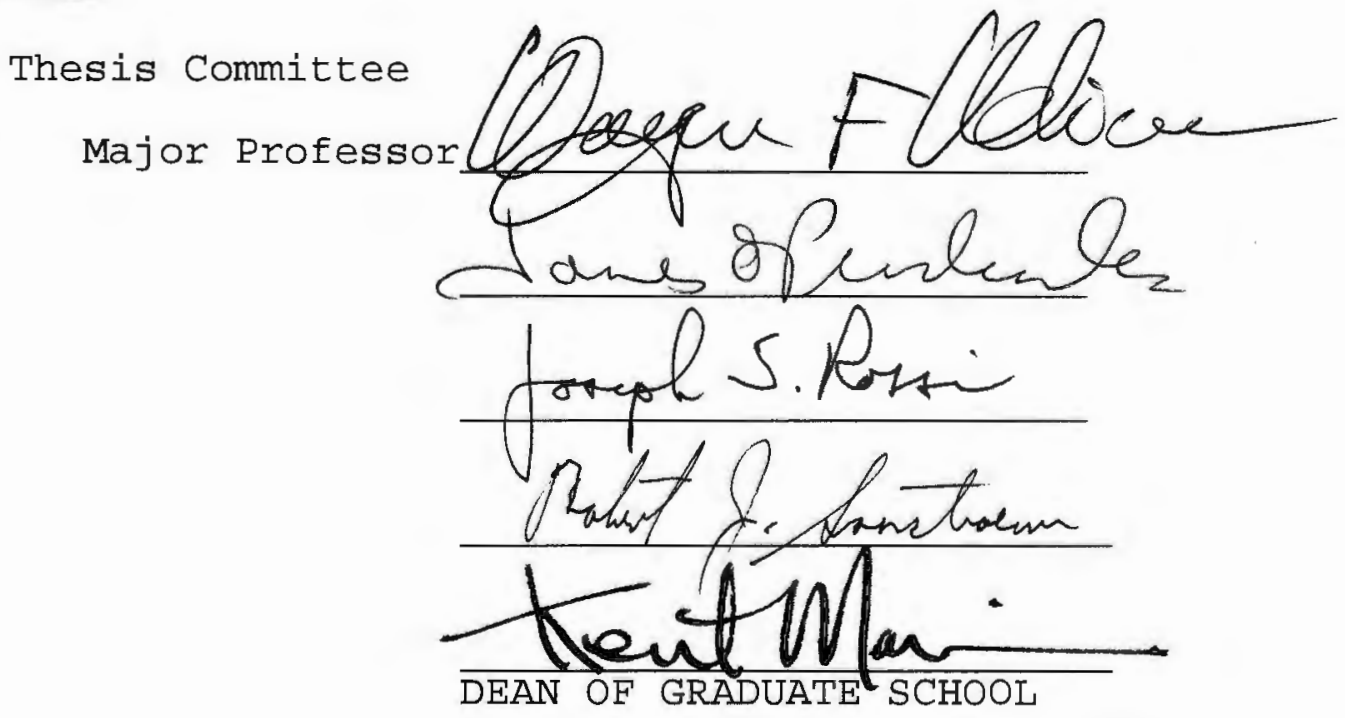


Abstract

This project is an examination of one of the first studies that applied the Transtheoretical Model of Behavior Change to the area of exercise. A core concept of the Transtheoretical Model is the temporal dimension represented by the stages of change. A variety of alternative staging methods have been developed. This study compared a continuous measure of stage membership and four discrete algorithms to stage exercise behavior in the context of a worksite program.

In Study I, a previously developed continuous measure of stage membership, the (URICA), was adapted to the area of exercise behavior (URICA-E). The structure of the instrument was replicated using Confirmatory Factor Analysis. One, two, three and four factor models were compared, and a correlated four factor model, representing the four stages of Precontemplation, Contemplation, Action and Maintenance, was found to have the best fit. Fit was improved by reducing the number of items. The 16 item version was confirmed in a second sample.

A Cluster Analysis was performed using the four standardized scale scores of the 16 item version of the URICA-E. Nine distinct clusters were found and replicated in a cross validation. Profiles were interpreted and found to have a number of similarities when compared to the profiles previously reported in population using the URICA. In study II, four discrete algorithms were examined 
both qualitatively and quantitatively. One of the algorithms, the Pproscal, produced distributions most similar to an alternative staging algorithm employed in a representative sample and was also judged to be the best on the basis of being well-defined and easy to answer.

In Study III, comparisons were made between the continuous measure, the URICA-E, and the discrete algorithm, the Pproscal. The profiles were compared and a confusion between Maintenance and Precontemplation was noted. This pointed out the critcal nature of the wording of the URICA-E questions. The Pproscal did not produce a high level of agreement in classifying stage when compared to the profiles, leading to the conclusion that the continuous measure is different from the discrete algorithm. The URICA-E (31 items, 16 item revised version, and the four scale scores) were compared with the Pproscal using discriminant function analysis. The 31 items produced the highest rates of correct classification.

Recommendations include: (1) using the long form of the URICA-E, (however, it requires a population that all acknowledge the presence of the problem behavior);

(2) external validation of the profiles produced by the cluster analysis, (appropriate variables would be the other constructs of the Transtheoretical Model (Pros and Cons, Confidence/Temptations, or Processes of Change) and measures of the problem behavior); and (3) preference for the Pproscal as the algorithm of choice. 


\section{Acknowledgment}

I wish to acknowledge Bess Marcus, whose devotion to exercise, got this data collected during a worksite smoking cessation study. Without the sample, there would have been no thesis.

I wish to thank Joe Rossi for his invaluable help in teaching me his technique of using Confirmatory Factor Analysis as an exploratory procedure.

I must thank Dr. Jeff Bellis for always being willing to answer my questions. He was the cheerful sharer of all his hard won knowledge and role model of what a senior graduate student should be.

I want to thank my daughter, Gabrielle, for putting up with me being in school. She has been very understanding of me wanting to follow my dream.

Most of all, I owe my major professor, wayne velicer, an eternal debt for sticking with me. Transformation is a painful process, but I truly believe that the final product will be worth it. 
Table of Content

Page Number

Abstract

ii

Acknowledgment

iv

Table of Contents

$\mathrm{v}$

List of Tables

vii

List of Figures

viii

Introduction

1

Exercise

4

Continuous Staging Measure: the URICA

4

Overview

6

Study I

7

Introduction

7

Method

7

Subjects

7

Procedure 8

Results

Principal Components Analysis

Confirmatory Factor Analysis (Replication) 13

Model Testing (31 Items) 13

Confirmatory Factor Analysis (Item Reduction) 18

Model Testing (16 Items) 22

Cluster Analysis 24

Maintenance $\quad 25$

$\begin{array}{ll}\text { Action } & 27\end{array}$

Decision Making $\quad 29$

Contemplation 1 
Page No.

Contemplation 2

Precontemplation 1

35

Precontemplation 2

37

Precontemplation 3

39

Uninvolved 1

41

Discussion

42

Study II .

48

Introduction

The Pladder

Critique of Pladder

The Pexscale

The Pexscpo

50

Critique of Pexscale \& Pexscpo

50

The Pproscal

51

Critique of Pproscal

51

Method

52

Subjects

52

Procedure

53

Results

53

Quantitative

53

Discussion

60

Study III.

63

Introduction

63

Method

Subjects

Procedure 
Page No

$$
\text { Results }
$$

Comparison of Profiles of URICA-E and

Pproscal

Comparison of 31 Items and Pproscal

71

Comparison of 16 Items and Pproscal

77

Comparison of Scale Scores and Pproscal

81

Discussion

81

Discussion

86

Appendix A

92

Appendix B

93

Appendix C

94

Appendix D

95

Appendix E

96

Appendix F

97

Bibliography

98 
List of Tables

Page Number

Table 1

Results of 31 Item CFA on Exploratory Sample

Table 2

Confirmatory Factor Analysis: Comparison of Fit Indices Table 3

Model Comparison using CFA (31 Items) on Exploratory Sample

Table 4

Model Comparison using CFA (16 Items) on Confirmatory Sample

Table 5

Stage Distributions of the 4 Algorithms

Table 6

Pladder by Pexscale Frequency Percentages

Table 7

Pladder by Pexscpo Frequency Percentages

Table 8

Pladder by Pproscal Frequency Percentages

Table 9

Pexscale by Pproscal Frequency Percentages

Table 10

Comparison of URICA-E Profiles by Stage of Pproscal 
Page No.

Table 11

Discriminant Function Analysis: Pproscal as group and 31 items of URICA-E as predictors classification Results

Table 12

Discrimianant Function Analysis:

Pproscal as Group and 16 Items of URICA-E

as predictor

Classification Results

Table 13

Discrimianant Function Analysis:

Pproscal as Group and 4 scale scores of URICA-E as predictor

Classification Results 
List of Figures

Page Number

Figure 1.

21

URICA-E Factor Loadings(ML estimates) for 16 Items

Figure 2.

Maintenance Profile

Figure 3 .

Action Profile

Figure 4.

Decision Making Profile

Figure 5 .

Contemplation 1. Profile

Figure 6 .

Contemplation 2. Profile

Figure 7 .

Precontemplation 1. Profile

Figure 8 .

Precontemplation 2. Profile

Figure 9.

Precontemplation 3. Profile

Figure 10.

Immotive 1. Profile

Figure 11.

Group Centroids Pproscal by 31 Items

Function 1 by Function 2 
Figure 12 .

Group Centroids Pproscal by 31 Items

Function 2 by Function 3

Figure 13

Group Centroids Pproscal by 16 Items

Function 1 by Function 2

Figure 14

Group Centroids Pproscal by 4 Scale Scores

Function 1 by Function 2 
The Transtheoretical Model and exercise behavior: a comparison of five staging methods.

The Transtheoretical Model of behavior change (Prochaska \& DiClemente, 1983) uses an amalgamation of latent constructs; Decisional Balance, Self-efficacy, Processes of Change and the Stages of Change, derived from a variety of sources. Each construct is operationalized by a measure composed of a series of items unique to a problem behavior. These items have been tested and refined to develop highly reliable instruments for a number of problem behaviors, with the most extensive work involving smoking cessation. This paper focuses on the measurement of the key organizing construct, the Stages of Change. Several alternative measures will be compared within the area of exercise.

\section{The Transtheoretical Model.}

Within the Transtheoretical Model, the dependent measures include the two scales from the Decisional Balance Measure, the Pros and Cons (Velicer, DiClemente, Prochaska, \& Brandenburg, 1985). These concepts are based on Janis and Mann's (1977) concept of decisional balance. A second set of dependent measures are the three scales of the Temptation or Self-efficacy measures (Velicer, DiClemente, Rossi, \& Prochaska, 1990). This measure is based on Bandura's (1977) self-efficacy construct which involves the degree of confidence a subject has that they will not engage in a 
problem behavior in tempting situations. The dependent measures also include the behaviors appropriate for a specific problem area.

The independent measures include the influences from the internal and external environment (including interventions) and ten Processes of Change (Prochaska, Velicer, Diclemente, \& Fava, 1988). The ten processes of change measured in the model are garnered from a review of psychotherapy techniques (Prochaska, 1984) and represent the behaviors, cognitions and emotions which the subjects engage in during the course of changing a behavior.

A core organizing concept, used in the Transtheoretical Model, is the temporal dimension represented by the stages of Change. In recent work, Velicer, Prochaska, Rossi \& Snow. (1992) conceptualize the five stages of change as: Precontemplation ( $P C$ ), a stage where no change in behavior is planned for at least the next 6 months; Contemplation (C), where change is planned within the next 6 months; Preparation (P), where change is planned in the next 30 days and some type of action has been attempted in the last year; Action (A), where change has begun and has been sustained for less than 6 months; and Maintenance (M), where change has been maintained for longer than 6 months.

Several prominent theories employ a stage concept as a central organizing construct. It has been used to organize and track the process of development. Piaget $(1960,1972)$ presented cognitive development as a series of 4 stages. 
Kohlberg (1976) laid out moral development as a series of 7 stages. Stage has also been used to break a complicated topic into more manageable units. Kubler-Ross (1969) used stages to analyze the complex period of dying. Her 5 stages could be moved through sequentially but, more often than not, the progress was variable. Some would become stuck in a single stage, others would fluctuate back and forth between stages. Stage can also be used to differentiate treatment modalities. The medical profession stages serious illnesses such as cancer in order to determine what protocol will be used as an intervention. Stage is used as an organizing tool, as an analytical instrument, and as an intervention guide by the Transtheoretical Model.

When the Transtheoretical Model moves into a new behavior area, such as exercise, the first task is to develop an efficient staging tool. Within the model, the stages have been measured in either of two ways: by a series of discrete questions (algorithm) or by a continuous measure. However, the relationship between these two different ways of assessing stage membership had not been empirically investigated. This study investigated the relationship between discrete and continuous staging methods by using a secondary analysis of several exercise data sets gathered as part of a larger worksite smoking cessation study (Marcus, Selby, Niaura, \& Rossi, 1992; Marcus, Rossi, Selby, Niaura, \& Abrams, 1992). The worksite study was one of the first use of the Transtheoretical Model in the area 
of exercise.

Exercise. When translating the Transtheoretical Model into a new area, such as exercise, it is important to take into account the ways that exercise differs from smoking, the behavior on which the model was developed. Exercise, unlike smoking, is a positive behavior that people are attempting to incorporate into their lives. It is not an easy behavior to maintain. Research shows that adherence to exercise is a major problem with 50\% of people who start programs, quitting before a year (Dishman, 1988). This implies that Maintenance is not a stable stage, as it often is for smokers. It is also suggested that exercise is not an allor-nothing phenomenon and that individuals who stop performing may intend to start again (Sonstroem, 1988). It seems that exercise can not easily reach termination. Termination is the point where, for smokers, they are not tempted in any situation. For exercisers, there is more movement back and forth among stages.

It has been surmised that this dynamic may be better captured by the use of a continuous staging measure rather than a discrete algorithm because the continuous measure reflects the proportion of each of the stages that come into play.

Continuous Staging Measure: the URICA. One approach that has been employed to stage people is a short questionnaire which is scored to produce four scales. The discrete stages can then be recovered by means of cluster analysis. A 
measure developed for this purpose is the University of Rhode Island Change Assessment (URICA) (MCConnaughy, Diclemente, Prochaska, \& Velicer, 1989; McConnaughy, Prochaska, \& Velicer, 1983). It is a short 32 item inventory which yields four highly reliable scales. It was used during psychotherapy to stage clients on whatever problem they were in therapy for. Appendix A presents a copy of these items.

Initially the stages of change were theorized as PC, C, $P, A$, and $M$ but $P$ was eliminated on the basis of the analysis. The four components accounted for 58\% of the total variance and Coefficient Alphas for the four scales ranged from .88 to .89. (MCConnaughy, et al., 1983). These findings were replicated where the same four components accounted for $45 \%$ of the total variance and the Cronbach's reliability coefficients for the four scales ranged from .79 to .84 (McConnaughy, et al., 1989).

McConnaughy and colleagues performed cluster analysis on both the initial sample and the replication sample. The initial work found 18 clusters. They named 7 major and 2 minor clusters: 1) Decision Making, 2) Maintenance, 3) Participation, 4) Pre-Participation, 5) Non-Contemplative Action, 6) Immotive, 7) Uninvolved, 8) Reluctance and 9) Non-Reflective Action. In the replication study the 8 cluster solution was chosen as the most clearly interpretable. The eight clusters were named: 1) Decision Making, 2) Participation, 3) Maintenance, 4) Immotive, 5) 
Precontemplation, 6) Uninvolved, 7) Discouraged and 8) Contemplation.

overview.

This study had three aims: 1 a) replication of a continuous staging measure, the (URICA), into the new area of exercise by using University of Rhode Island Change Assessment for Exercise (URICA-E) in order to establish the internal validity of the instrument, 1 b) reduction of the number of items to lessen response burden on the subject, and 1 c) generation of profiles of subtypes of changers. (Study I.); 2) the investigation of four alternative staging algorithms: Pladder, Pexscale, Pexscpo and Pproscal (Study II.); and 3) an assessment of the relationship between the URICA-E and the best of the four algorithms (Study III.).

Study $I$. is a replication of the work of McConnaughy and colleagues. It uses the URICA-E gathered on a worksite sample. Part 1 replicates the instrument. Part 2 refines the instrument. Part 3 generates profiles of changers.

Study II. will evaluate four different algorithms for staging subjects by examining both qualitative and quantitative differences and similarities.

Study III. will assess the relationship between the continuous measure of change, the URICA-E, and one of the four discrete algorithms. 


\section{Study I. URICA-E, a Replication of the URICA}

\section{Introduction}

Replication of the URICA in a new area, exercise, served three purposes. First, it validated the usefulness of the Transtheoretical Model in the acquisition of positive behaviors, as opposed to the cessation of a negative problem behavior like smoking. Secondly, it determined whether the 31 items of the URICA-E could be decreased to a smaller, but as efficient number of items. Note: In the administration of the URICA-E, item A 20 was inadvertently left out so the instrument contained only 31 items. These questions were answered by using Principal Components Analysis and Confirmatory Factor Analysis. Thirdly, a Cluster Analysis of subjects using the scale scores from the URICA-E was employed to determine if discrete subtypes exist. The graphing of the mean scores for the 4 stage scores of a cluster produced a visual picture of different subtypes of changers.

\section{Method}

Subjects. The URICA-E was collected on 936 subjects from 4 worksites (Landmark Medical Center (N-198), the Post Office (N-443), Ann and Hope (N-195) and MSA Manufacturing (N-100)) as part of a larger assessment package. The sample was $50.7 \%$ female, $95.9 \%$ white, $68 \%$ married, $55.7 \%$ attended college, $71.5 \%$ had family income of $\$ 30,000$ and above and their age ranged from 17 to 70 (M-40.8). Marcus, Emmons, 
Abrams, Marshall, Kane, Etzel, \& Novotony (1992) provide an extensive description of the sample and the purpose of the original studies.

Procedure. Means, standard deviations, and frequencies were calculated. Skewness and kurtosis were assessed. All values fell within an acceptable range. Since the data set was large, any subjects with missing data were deleted from the analysis. The data set was then split into two samples: odd identification numbers becoming the first or exploratory sample $(N=474)$ and even numbers becoming the second or confirmatory sample $(\mathrm{N}=462)$. The split produced two extremely similar samples with regard to demographic characteristics.

Using the exploratory sample, the component structure was analyzed using Principal Components Analysis (PCA) in replication of the work done by McConnaughy, et al. (1983) and McConnaughy, et al. (1989). The number of components to extract was based on MAP (minimum average partial) (Velicer, 1976) procedure and Horn's (1965) Parallel Analysis as well as guided by theoretical consideration as to the number of expected components. Different solutions, ranging from 3 through 6 components, were interpreted.

Since Principal Component Analysis did not produce a clear component structure, an alternative analysis procedure was employed which permitted the use of existing theoretical knowledge to guide the analysis: Confirmatory Factor Analysis (CFA), using Structural Equation Modeling (Bentler, 
1989; Joreskog \& Sorbom, 1989). The procedure was to use LISREL VII (Joreskog \& Sorbom, 1990) to fit the data to a correlated four factor model and to test it for goodness of fit in comparison to competing models. A correlated four factor model is consistent with the results found for other health behaviors (McConnaughy, et al., 1983; McConnaughy, et al., 1989; DiClemente \& Hughes, 1990).

The overall fit indices included: Chi-square, Root Mean Square Residual (RMSR) (Joreskog \& Sorbom, 1986), Goodness of Fit Index, (GFI) (Joreskog \& Sorbom, 1986), Comparative Fit Index, (CFI) (Bentler, 1990) and the Incremental Fit Index type 2, (IFI) (Mulaik et al., 1989). Different fit indices were employed since no consensus exists about which is the best. The comparative fit index and the Incremental Fit Index are presently the most popular.

In addition to the hypothesized correlated four factor model, six other possible models, using all 31 items, were tested on the exploratory sample. The models tested were:

(1) a one factor model that conceptualizes change as a single dimension; (2) an uncorrelated and (3) correlated two factor model that saw change as action versus no action; (4) an uncorrelated and (5) correlated three factor model based on Stern et al(1987) that differentiated people who have no intention of changing, (PC); from those who are thinking and perhaps making some change, ( $C \& A)$; and from those who have been changed for some time, (M); and finally (6) an uncorrelated four factor model. In addition the Null Model 
was fit for comparison purposes.

The URICA-E was then analyzed to see if a more parsimonious version i.e., involving fewer than 31 items, could be used to stage people as efficiently and also improve the fit of the model. During this process analyses were run using the correlated four factor model and deletion of items occurred. Items were dropped if they had low factor loadings, loaded on more than one factor (complex items) or were theoretically inconsistent. The gauge used to measure change in fit was the overall fit indices. The factor loadings and the modification indices function as indicators to determine what items to delete.

The modification indices in general represent the "expected drop in Chi-square if a particular parameter were freely estimated" (Byrne, 1989, p. 57). Modification indices are normally used to re-specify a model that is fitting poorly. The indices point out the elements, that if freed, would lead to the greatest improvement in fit. It is analogous to some variants of stepwise regression where the variable that adds most to the explained variance of the dependent variable is added first and then the variable that adds the most to the revised equation is added next, until no other variables lead to a significant increment in $R$ squared (Bollen, 1989).

The modification indices for the factor loadings can be interpreted as a measure of complexity. Each non-estimated item is given a modification index for the loadings on the 
four factors. High values for modification indices on nonloading factors indicate an item that shows complexity. Removal of complex items improves both the fit and the reliability of a construct.

The matrix of modification indices for the measurement errors pinpoints pairs of items which, if the correlation of the residuals was freed, would reduce the Chi-square. The maximum modification index points out the two items whose correlation of their residuals cause the largest amount of change in the Chi-square. Deletion of at least one of these items can reduce the Chi-square value.

The use of modification indices is a procedure that capitalizes on error variance to improve the fit of the model to the data. So, uncritical reliance on modification indices to modify a model can have serious consequences and lead to acceptance of an incorrectly specified model (Kaplan, 1989; MacCallum, 1986; Silva \& MacCallum, 1988). Cross validation of the final model by replicating it in a separate sample can protect against this danger (Marcus, Rossi, Selby, Niaura \& Abrams, 1992).

Using the revised, parsimonious version which had been developed, the other models were tested again using the confirmatory sample to ensure that the correlated four factor model was indeed the best fitting model. The same seven models were tested as described previously. The seven models were compared using the previously described fit indices. 
Lastly, scale scores for the URICA-E were formed by calculating the unweighted sum of the scores on the 4 items allocated to each stage then dividing the total by 4 . This score was standardized to a T-score metric (mean of 50 and a standard deviation of 10). Each subject therefore had 4 standardized T-scores, one for each stage.

A Cluster Analysis was performed on this data to determine if different types of changers exist, following McConnaughy et al.(1983, 1989). Although the four scales were somewhat correlated, a Euclidean distance measure was employed. The clustering method was Ward's (1963). Three through fourteen clusters were examined. Decisions on how many clusters to interpret were made using the cubic clustering criterion, investigation of the dendogram, and comparison to the previous profiles (McConnaughy, et.al., 1983; McConnaughy, et al., 1989).

Three samples were clustered. They were the Total Sample from Landmark, Ann \& Hope, Post Office, and MSA (N936), Sample 1 from Landmark, Ann \& Hope, and MSA (N-484), and Sample 2 from the Post Office (N-415).

Results

Principal Component Analysis (PCA). Using the exploratory sample, the component structure was analyzed using Principal Components Analysis (PCA). The MAP 
procedure (Velicer, 1976), and Parallel Analysis (Horn, 1965; Lautenschlager, 1989) both recommended a 4 component solution. The results of the varimax rotated four component solution were far from clear but they did give some valuable pointers as to which items had high loadings and which items had an affinity for each other. An oblique rotation (DQuart, BMDP 4M), resulted in Component one having high positive loadings for PC-01, PC-05, PC-11 and PC-13 as well as high negative loadings for C-02, C-04, C-08 and C-15. Component Two had high loadings for A-03, A-10, A-14, A-17 as well as three other A items and M-06, M-18, and M-32. Component Three had M-22 and $3 \mathrm{C}$ items. Component Four contained 4 PC items. The Promax rotation (CAX program; Velicer, Fava, Harrop \& Zwick, 1991) produced an identical solution except that PC-23 loaded on component one instead of component four. The coefficient alphas, a measure of reliability (Cronbach, 1951) for the total 31 items, were: $\mathrm{PC}=.76, \mathrm{C}=.90, \mathrm{~A}=.86$, and $\mathrm{M}=.87$.

Confirmatory Factor Analysis (CFA-Replication). Since Principal Component Analysis did not produce a clear component structure, a further assessment of factor structure was attempted using Confirmatory Factor Analysis (CFA) .

Model Testing. Seven models were fit to the data. Table 1 presents the five goodness of fit indices for the seven models. The seven models were (1) a correlated four factor model; (2) an uncorrelated four factor model; (3) a 
correlated three factor model; (4) an uncorrelated three factor model; (5) a correlated two factor model; (6) an uncorrelated two factor model; and (7) a one factor model. The correlated four factor model, although a poor fit, did a better job of fitting the data than any of the 6 other models. 
Table 1

Model Comparison using CFA (31 Items) on Exploratory Sample

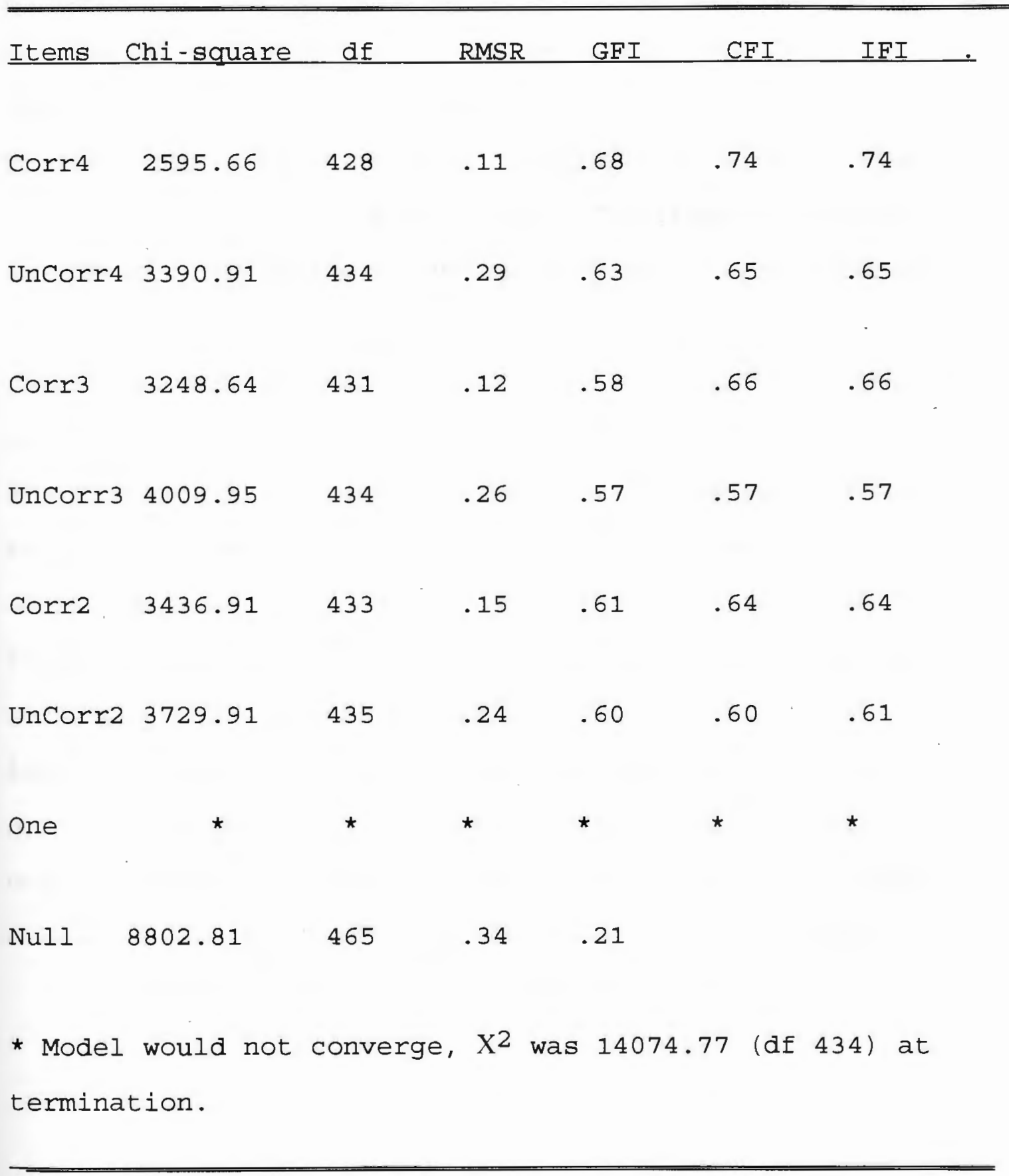


In the 31-item CFA results, the ratio of Chi-square to df was over 6 to $1(2595.66$ to 428$)$. It is recommended that a ratio of Chi-square to df be less than 2 to 1 (Joreskog \& Sorbom, 1979) or at least less than 5 to 1 (Hayduk, 1987). The RMSR (.112) was well over .06 which is the acceptable limit for good fit (Hayduk, 1987). The Comparative Fit Index (.740) was poor being no where near .90, the minimum desired value for good fit (Bentler, 1990).

The standardized solution did produce four fairly clear correlated factors (see Table 2). Factor One had all the PC items with only $\mathrm{PC}-26, \mathrm{PC}-29$ and $\mathrm{PC}-31$ loading very poorly and the rest between .80 and .48 . Factor Two had $C$ items all loading between .85 and .56 . Factor Three had A-30 loading poorly while all of the rest of the $A$ items loaded between .80 and .51. Factor Four had all the M items loading between .82 and .55 . This suggests that the hypothetical model, the correlated four factor model, is the correct model, but some of the manifest variables (items) are not contributing to the overall fit of the model. 
Table 2

Standardized Pattern Matrix

Results of 31 Items CFA on exploratory sample

Latent Variables

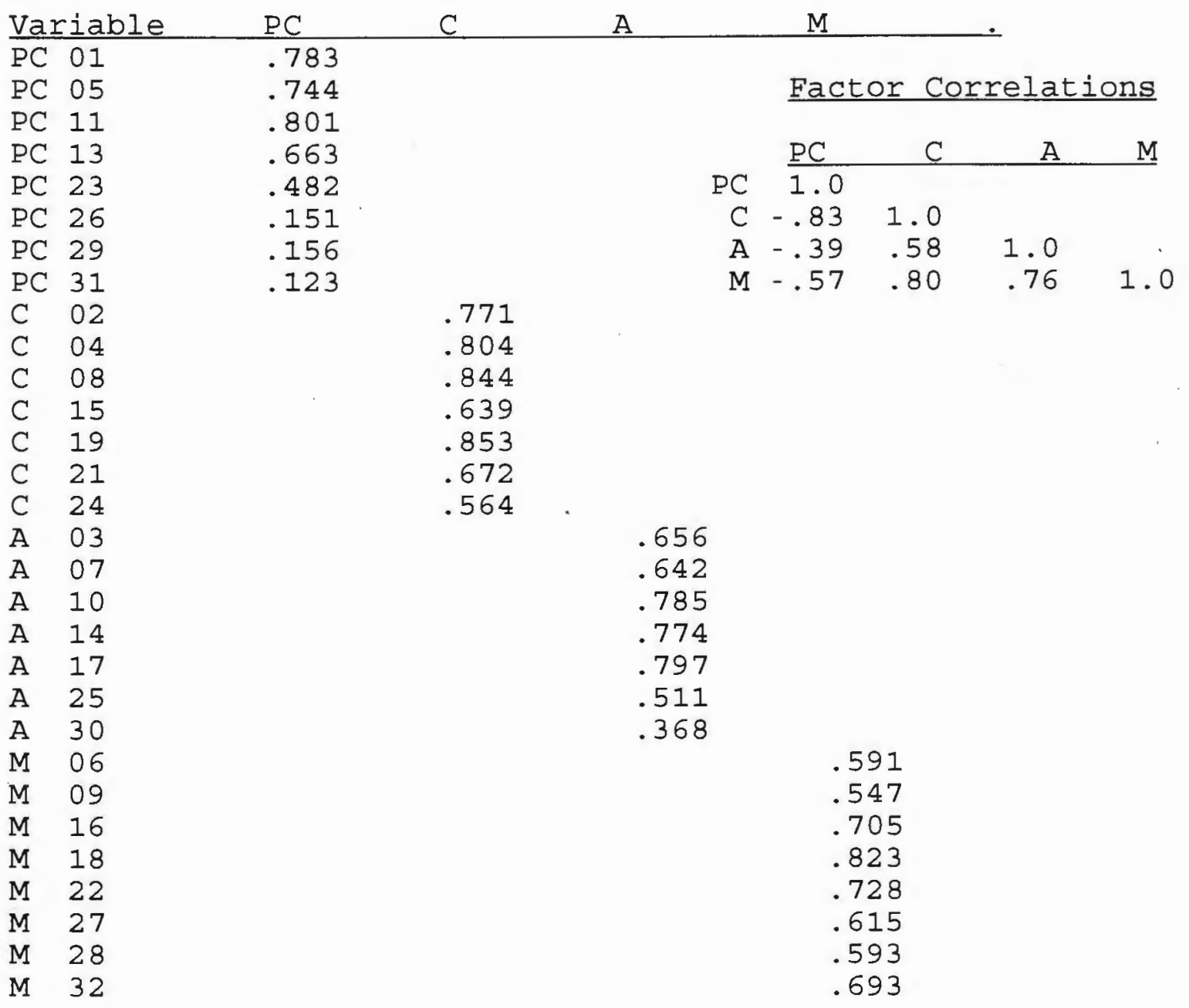


Confirmatory Factor Analysis (Item Reduction). Since 31 items creates a significant response burden on the participants and the fit of the 31 items was poor, the URICA-E was analyzed to see if a more parsimonious version could be used to stage people as efficiently and to attain a better fitting model. Item deletion was implemented in a stepwise fashion. An evaluation of the overall fit indices, the standardized solution, reliabilities and the modification indices of importance led to a stepwise reduction in the number of items from 31 to 23 to 21 to 20 to 19 to 18 to 15 to 14 to 12 and back up to 16 . See Table 3 for a comparison of model fit for the different number of items. 
Table 3

Confirmatory Factor Analysis: Comparison of Fit Indices A Correlated Four Factor Solution with Different Item Pools

\begin{tabular}{|c|c|c|c|c|c|c|}
\hline Items & Chi-square & $d f$ & RMSR & GFI & CFI & IFI \\
\hline 31 & 2595.66 & 428 & .112 & .683 & .740 & .741 \\
\hline 23 & 982.18 & 224 & .067 & .798 & .877 & .878 \\
\hline 21 & 677.61 & 183 & .061 & .873 & .912 & .913 \\
\hline 20 & 508.34 & 164 & .047 & .899 & .935 & .936 \\
\hline 19 & 424.52 & 146 & .045 & .914 & .943 & .943 \\
\hline 18 & 353.76 & 129 & .043 & .923 & .952 & .952 \\
\hline 15 & 197.04 & 84 & .036 & .947 & .971 & .972 \\
\hline 14 & 162.26 & 71 & .033 & .953 & .976 & .976 \\
\hline 12 & 65.17 & 48 & .019 & .978 & .994 & .994 \\
\hline 16 & 273.53 & 98 & .038 & .928 & .960 & .960 \\
\hline
\end{tabular}


With each deletion, the fit had improved, but the number of items per construct also had to be taken into consideration. A comparison was made between the 12 item and the 16 item solution. The pros of a 12 item solution were the greater overall fit (Chi-square 65.17, df 48, CFI $=.994$ ) and the reduced response burden on the subject. The cons of the 12 item solution were the slight reduction in reliability $(\mathrm{P}=.79, \mathrm{C}=.88, \mathrm{~A}=.83$ and $\mathrm{M}=.81)$ and only 3 items per construct, the minimum required for identification (Anderson \& Rubin, 1957). The pros of the 16 item solution were that the fit was acceptable (Chi-square 273.53, df 98, CFI-.960), the reliabilities were acceptable ( $\mathrm{PC}=.83, \mathrm{C}=.90$, $A=.84$, and $M=.83$ ) and there were 4 items per construct. The response burden of 16 items was less of a con than having only 3 items per construct. Thus, the 16 item solution was chosen to replicate with the confirmatory sample. See Figure 1 for the 16 items chosen and maximum likelihood estimates (factor loadings) for the confirmatory sample. 
Figure 1. URICA-E 16 Items

Factor Loadings (ML Estimates)
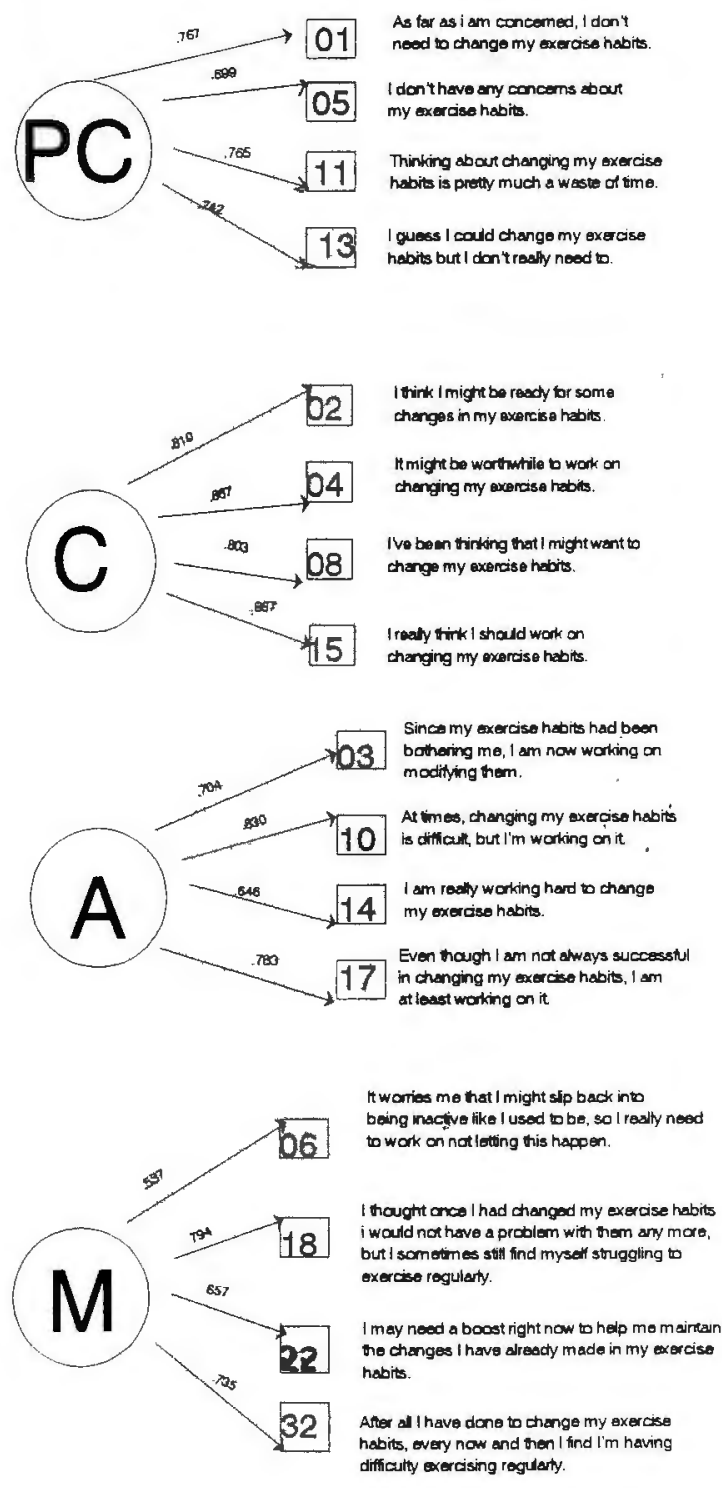
Model Testing. Using the confirmatory sample and the revised 16 item version, the correlated four factor model was again tested against the other 6 models (uncorrelated 4 factor, correlated and uncorrelated 3 factor, correlated and uncorrelated 2 factor and one factor). The correlated four factor model resulted in the best fit with a Chi-square of 268.75, df 98, RMSR $=.038$ and $\mathrm{CFI}=.96$. This endorsed the idea of four stages ( $\mathrm{PC}, \mathrm{C}, \mathrm{A}$ and $\mathrm{M}$ ) that are related one to the other. See Table 4 for a comparison of the models tested and correlations between factors for the correlated. four factor model. 
Table 4

Model Comparison using CFA (16 Items) on Confirmatory Sample

\begin{tabular}{|c|c|c|c|c|c|c|}
\hline Items & Chi-square & df & RMSR & GFI & CFI & IFI \\
\hline Corr4 & 268.75 & 98 & .038 & .930 & .957 & .958 \\
\hline UnCorr4 & 1239.80 & 104 & .359 & .741 & .725 & .726 \\
\hline Corr 3 & 605.72 & 101 & .068 & .828 & .877 & .878 \\
\hline UnCorr3 & 1282.87 & 104 & .327 & .747 & .715 & .716 \\
\hline Corr2 & 800.12 & 103 & .080 & .758 & .831 & .832 \\
\hline UnCorr2 & 1256.75 & 104 & .263 & .715 & .721 & .722 \\
\hline One & 1157.88 & 104 & .177 & .729 & .745 & .746 \\
\hline Null & 4250.51 & 120 & .432 & .240 & & \\
\hline
\end{tabular}

Factor Correlations for 4 Factor Model

\begin{tabular}{lllll} 
& $\mathrm{PC}$ & $\mathrm{C}$ & $\mathrm{A}$ & $\mathrm{M}$ \\
\hline $\mathrm{PC}$ & 1.0 & & & \\
$\mathrm{C}$ & -.88 & 1.0 & & \\
$\mathrm{~A}$ & -.60 & .71 & 1.0 & \\
$\mathrm{M}$ & -.64 & .75 & .84 & 1.0.
\end{tabular}




\section{Cluster Analysis. Using the three samples (Total,}

$\mathrm{N}=936$; Sample 1, $\mathrm{N}=484$; and Sample 2, $\mathrm{N}=415$ ), a cluster analysis was performed using the standardized scale scores of the 16 item version of the URICA-E. Separate analyses were done on each of the three samples. The shape, elevation and scatter of the profiles were the characteristics compared between samples to validate the existence of subtypes of changers. Decisions on how many clusters to interpret were made using the cubic clustering criterion, investigation of the dendogram, and comparison to the previous profiles (McConnaughy, et.al., 1983;

McConnaughy, et al., 1989). The degree of replication across the three samples was remarkable.

Choosing the correct number of profiles is a difficult task for which no single method is broadly accepted as correct. Two numeric methods are the cubic clustering criterion and the dendogram. The cubic clustering criterion is a numeric value that starts out as a positive number, descends to zero, and starts to grow negatively. When this number disrupts its linear sequence and starts to bobble, it is around the number of clusters that should be interpreted. Interpreting the dendogram is also an inaccurate experience. It is around the number of first level breaks, depicted on a schematic representation of the scores, that indicates the number of clusters to interpret. With the numeric criterion so vague, more dependence was put on choosing the number of clusters that kept strong profiles intact. Based on these 
three criteria, eleven clusters were retained in each sample, but only nine were interpreted. The tenth and eleventh clusters were each only found in one sample. This failure to replicate precluded interpretation.

Naming of clusters is influenced heavily by previous work and the researcher's personal interpretation. The nine distinct subtypes were named: (1) Maintenance, (2) Action, (3) Decision Making, (4) Contemplation 1, (5) Contemplation 2, (6) Precontemplation 1, (7) Precontemplation 2, (8) Precontemplation 3 , and (9) Uninvolved.

Maintenance. A cluster with the same profile was found in each of the three samples and was labeled Maintenance (see Figure 2). In this profile, the score on PC is extremely low, approximately one and a third standard deviations below the mean. The scores on $\mathrm{C}, \mathrm{A}$; and $\mathrm{M}$ scales are all almost equal and slightly more than one standard deviation above the mean. Subjects with this profile are clearly not denying the problem. They are currently exercising and also contemplating or taking action on increasing their exercise. 
Figure 2. URICA-E MAINTENANCE PROFILE

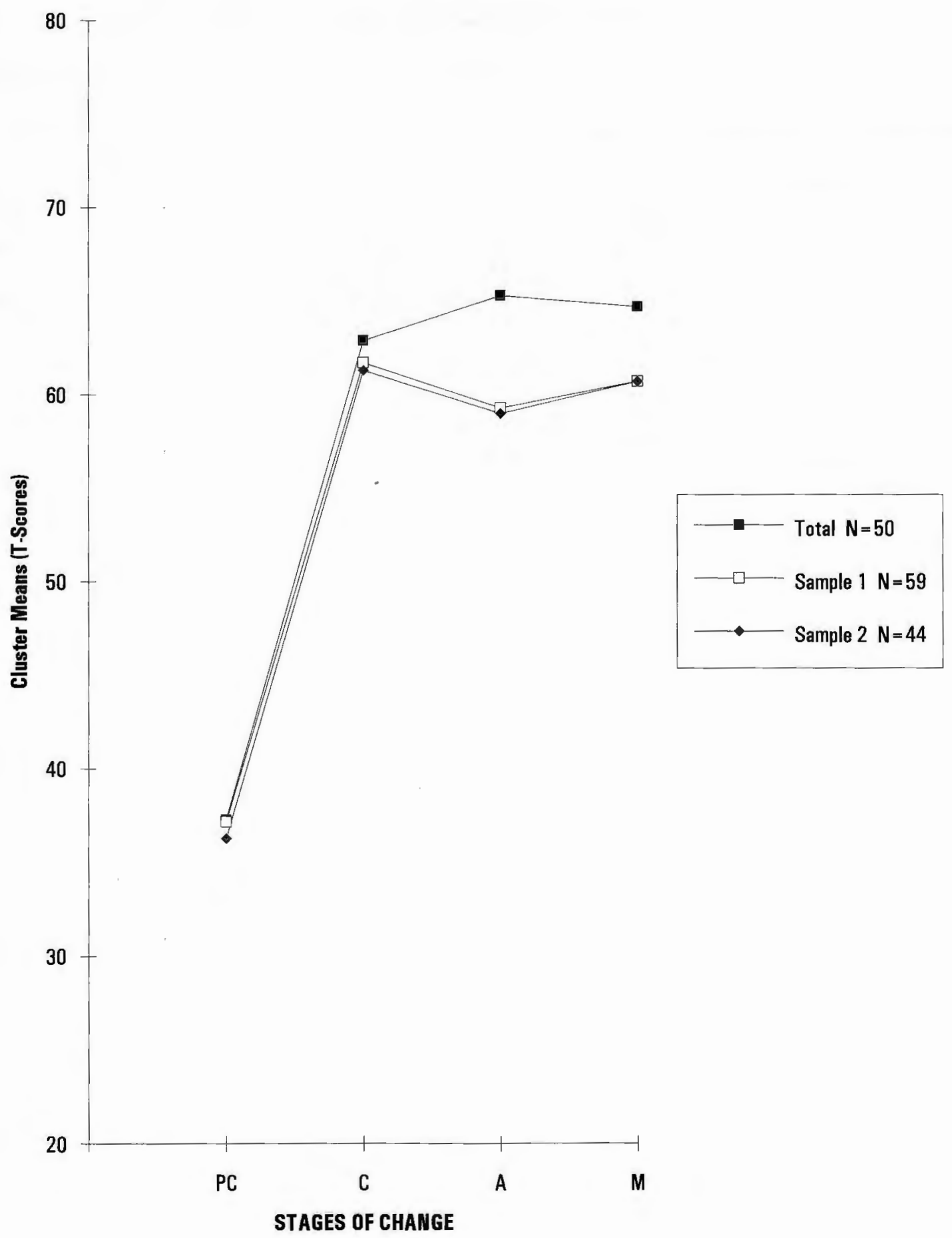


Action. In all three of the samples, a profile was found and labeled Action (see Figure 3). In this profile, the score on PC is slightly below the mean. The scores on $\mathrm{C}$ are slightly above the mean whereas $A$, and $M$ scales are all almost equal and approximately one standard deviation above the mean. Subjects with this profile are exercising regularly but the struggle to maintain this behavior still remains something to think about. 
Figure 3. URICA-E ACTION PROFILE

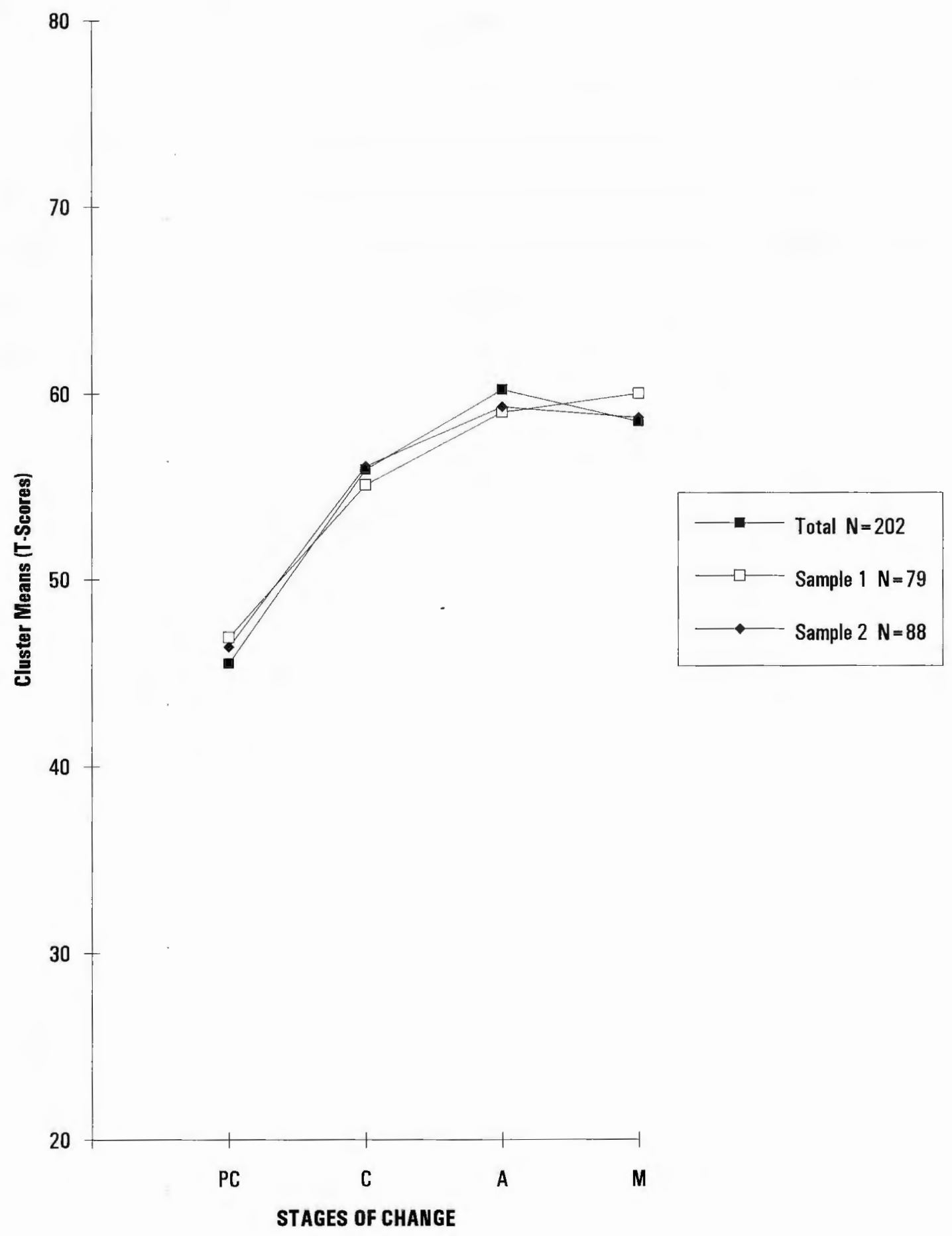


Decision Making. A cluster with the same profile was found in each of the three samples and was labeled Decision Making (see Figure 4). In this profile, the score on PC is nearly a standard deviation below the mean. The scores on $C$ and $A$ are nearly a standard deviation above the mean. M scale scores are down slightly below the mean. subjects with this profile are experimenting with exercising. They are putting a lot of thought and energy into initiating an exercise program. 
Figure 4. URICA-E DECISION MAKING PROFILE

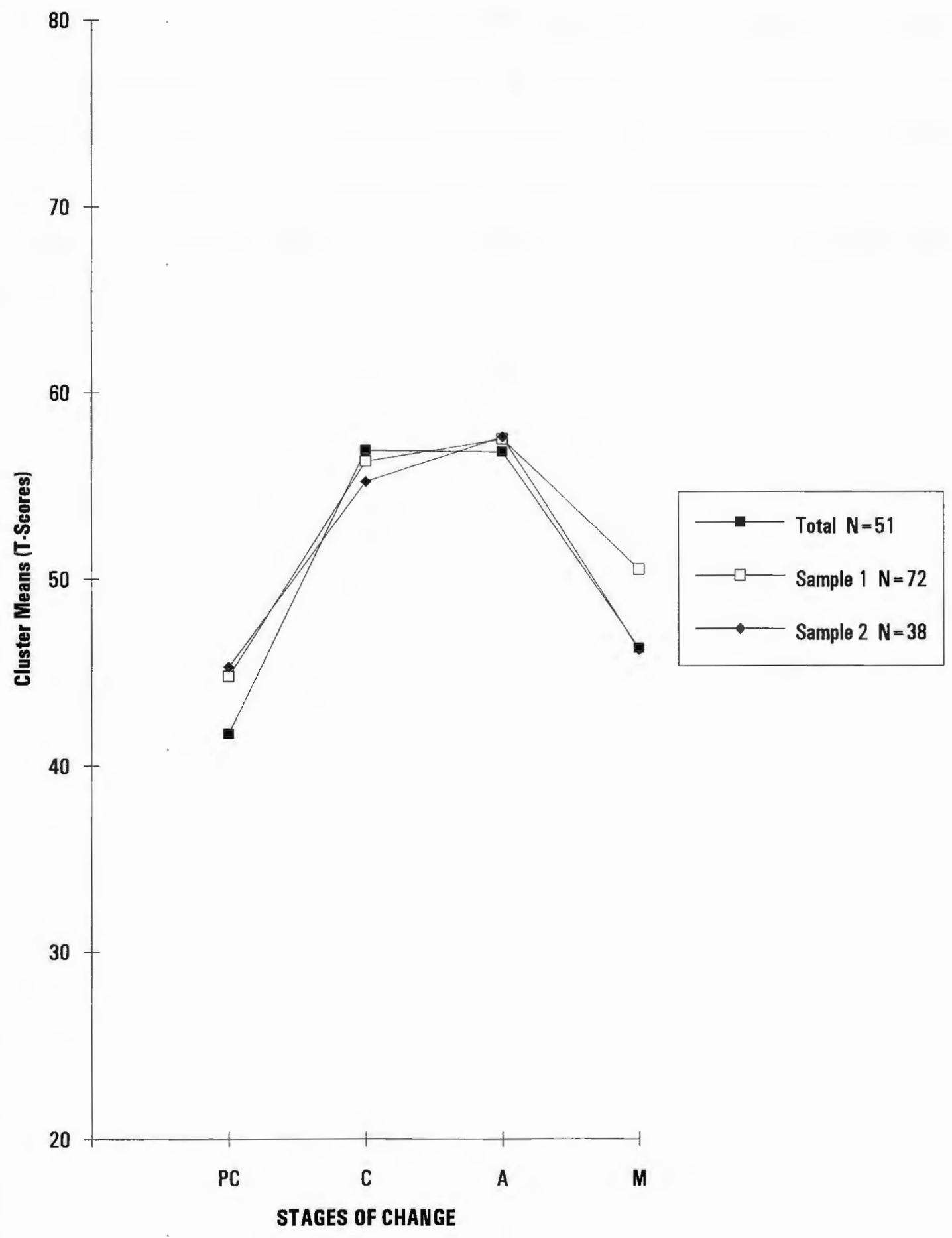


Contemplation 1. In each of the three samples, a cluster was found and was labeled contemplation 1. (see Figure 5). In this profile, the score on PC is nearly a half a standard deviation below the mean. The scores on $\mathrm{C}$ are nearly a half a standard deviation above the mean. A and $\mathrm{M}$ scale scores are also below the mean. Subjects with this profile are thinking a great deal about exercise, but they are not yet doing anything. 
Figure 5. URICA-E CONTEMPLATION 1 PROFILE

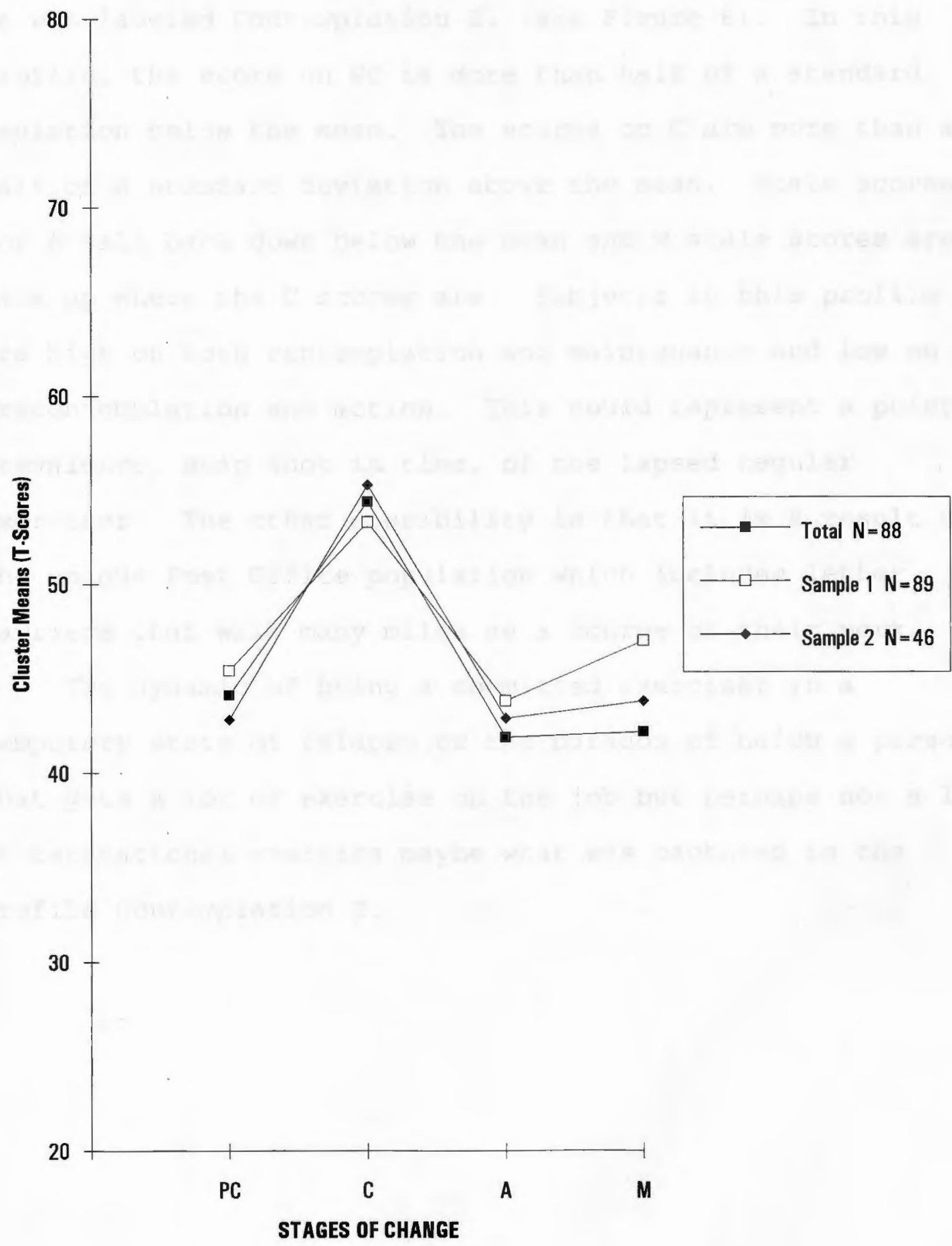


Contemplation 2. A cluster with the same profile was found in only two of the three samples (Total and Sample 2). It was labeled Contemplation 2. (see Figure 6). In this profile, the score on PC is more than half of a standard deviation below the mean. The scores on $\mathrm{C}$ are more than a half of a standard deviation above the mean. Scale scores for A fall back down below the mean and M scale scores are back up where the C scores are. Subjects in this profile are high on both contemplation and maintenance and low on precontemplation and action. This could represent a point prevalence, snap shot in time, of the lapsed regular exerciser. The other possibility is that it is a result of the unique Post Office population which includes letter carriers that walk many miles as a course of their work. The dynamic of being a committed exerciser in a temporary state of relapse or the paradox of being a person that gets a lot of exercise on the job but perhaps not a lot of recreational exercise maybe what was captured in the profile Contemplation 2 . 
Figure 6. CONTEMPLATION 2 PROFILE

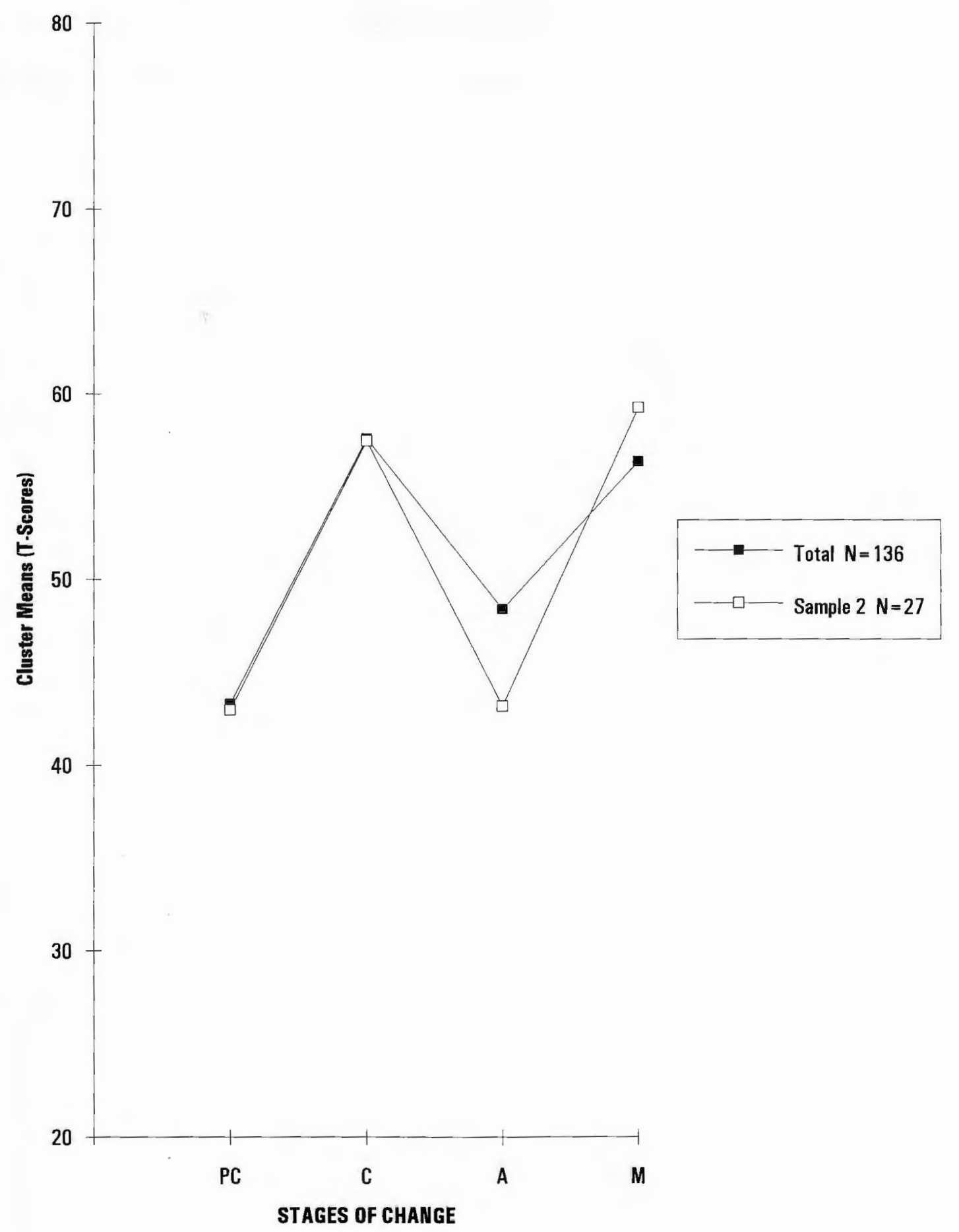


Precontemplation 1. Found in all three of the samples, was a cluster that was labeled Precontemplation 1. (see Figure 7). In this profile, the score on PC is more than a standard deviation above the mean. The scores on $\mathrm{C}$ are more than a standard deviation below the mean. Scale scores for $A$ and $M$ are also below but closer to the mean. Subjects in this profile evidence difficulty in coming to the realization that exercise is a problem for them. They are doing some thinking. Turmoil comes to mind when examining this profile. 
Figure 7. URICA-E PRECONTEMPLATION 1 PROFILE

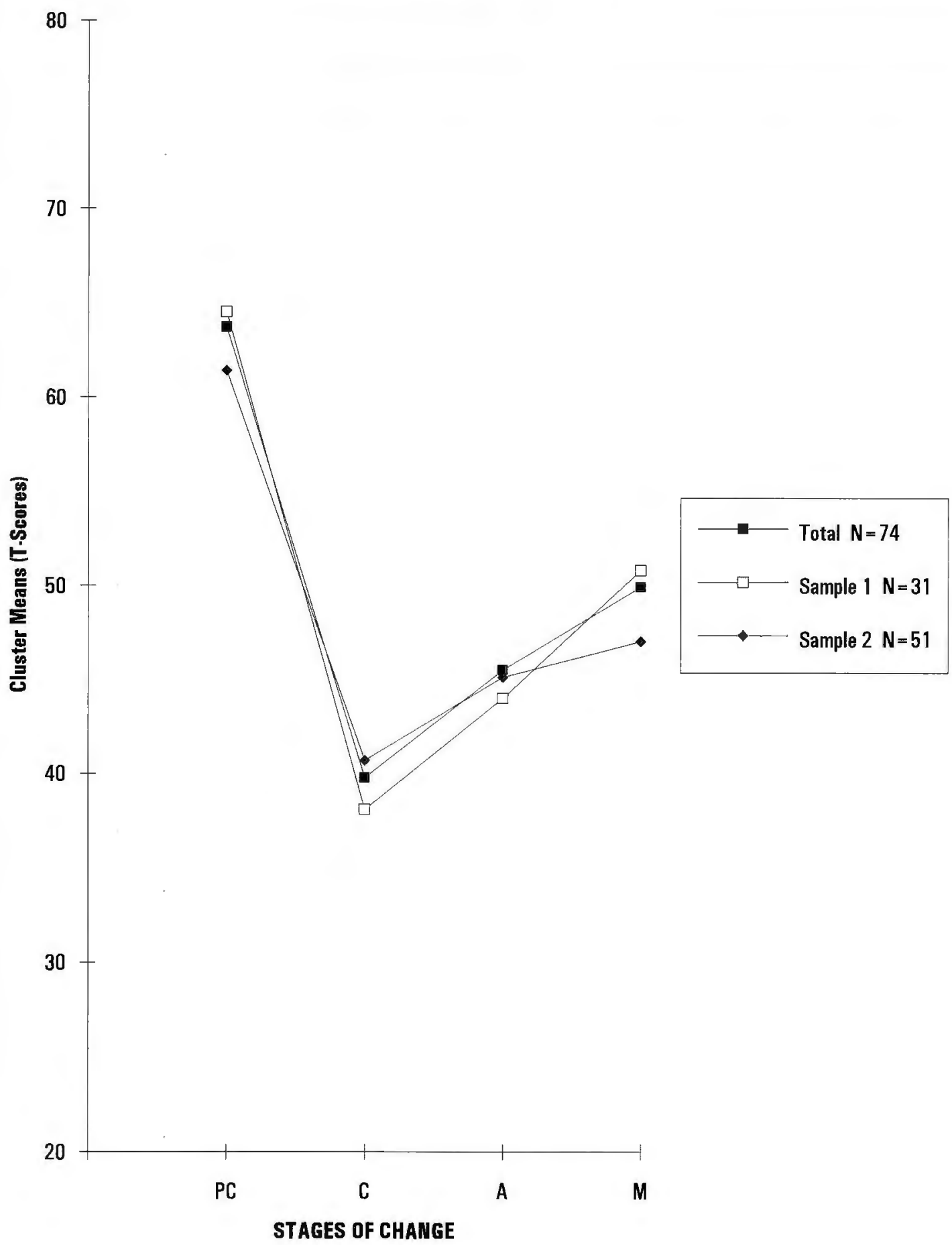


Precontemplation 2. A cluster with the same profile was found in all three of the samples. It was labeled Precontemplation 2. (see Figure 8). In this profile, the score on PC is more than one and a half standard deviations above the mean. The scores on $\mathrm{C}, \mathrm{A}$ and $\mathrm{M}$ are more than $\mathrm{a}$ standard deviation below the mean. Subjects in this profile are doing very little thinking or acting. They are caught in a state of being immotive. 
Figure 8. URICA-E PRECONTEMPLATION 2 PROFILE

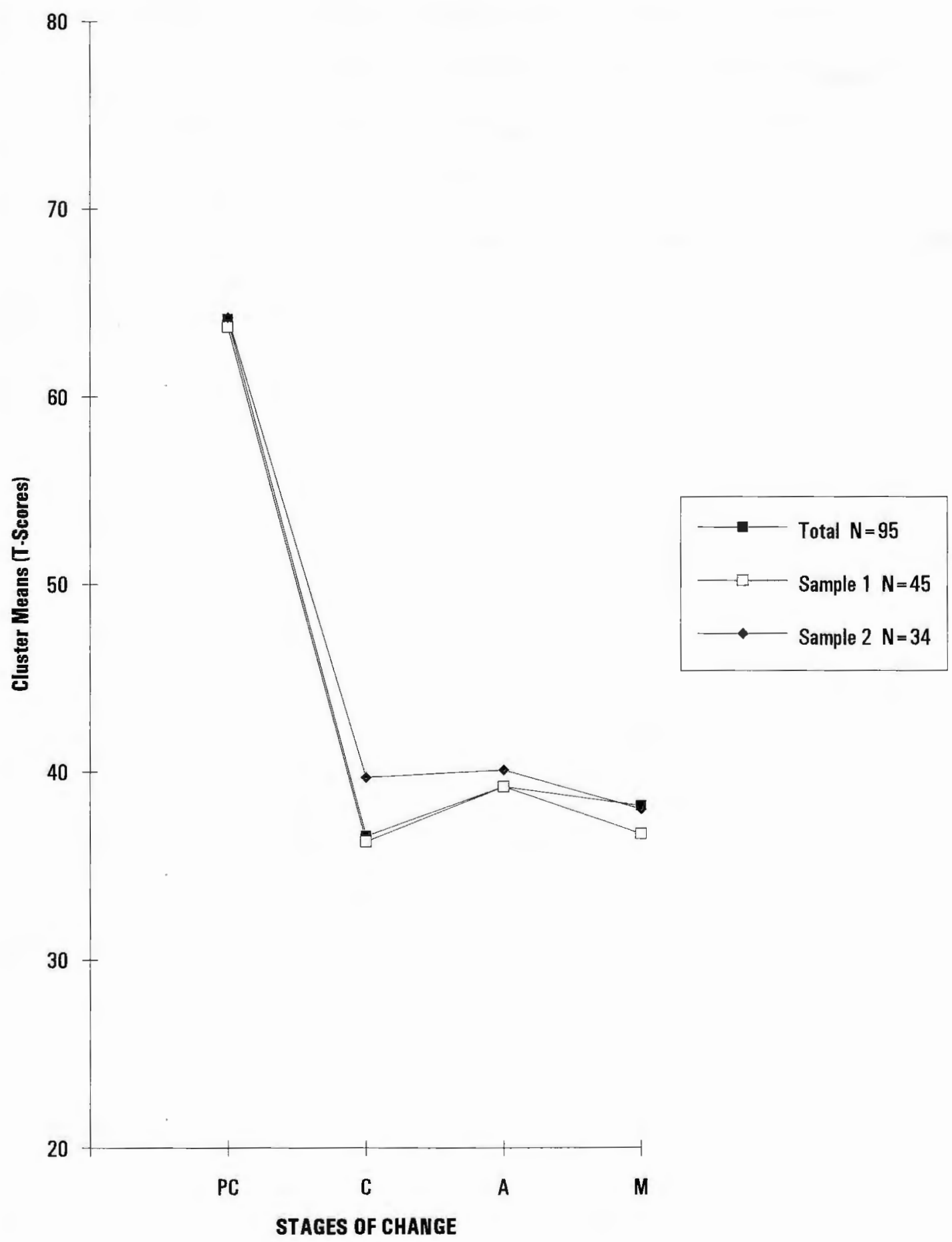


Precontemplation 3. In all three of the samples, a cluster with the same profile was found and labeled Precontemplation 3. (see Figure 9). In this profile, the score on PC is extremely high, from one to two standard deviation above the mean. The scores on $\mathrm{C}, \mathrm{A}$ and $\mathrm{M}$ are more than two standard deviation below the mean. Subjects in this profile are not even thinking about exercise let alone exercising. They seem to be in a state of denial about exercise. 
Figure 9. URICA-E PRECONTEMPLATION 3 PROFILE

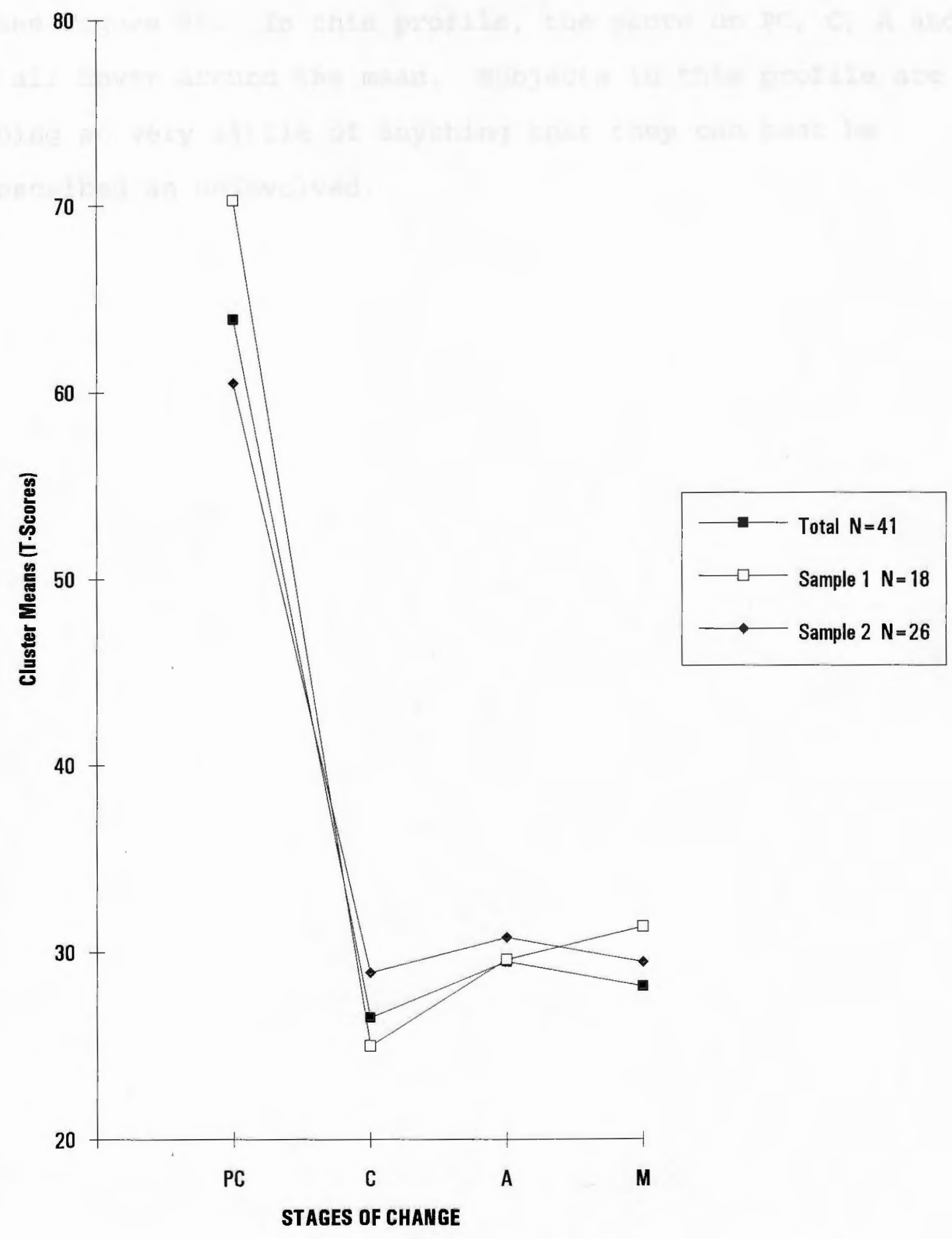


Uninvolved 1. A cluster with the same profile was found in all three of the samples. It was labeled Uninvolved 1. (see Figure 9). In this profile, the score on PC, C, A and $M$ all hover around the mean. Subjects in this profile are doing so very little of anything that they can best be described as uninvolved. 
Figure 10. URICA-E UNINVOLVED PROFILE

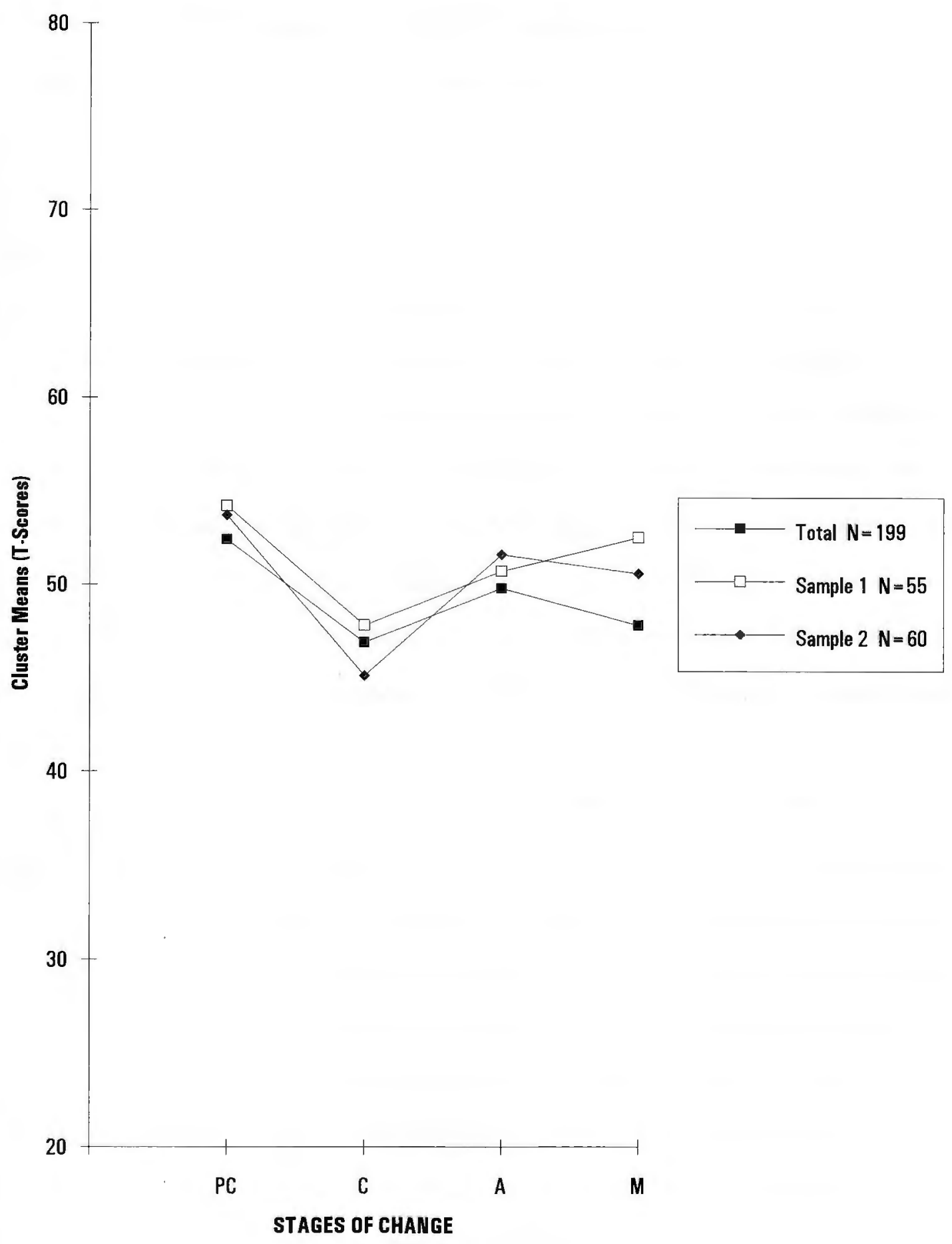


Discussion

Study I. was a replication and a refinement of the URICA for a different behavior, exercise. Principal Component Analysis, the analytical tool used with the URICA did not perform as well with the URICA-E. Using the results of McConnaughy and colleagues as a guide, the choice was made to use Confirmatory Factor Analysis on a correlated four factor model. The correlated four factor model resulted in a better fit than 6 other possible models. The fit resulting from the 31 item solution was not adequate (CFI=.741), but the factor structure showed a nucleus of items for each factor that loaded well. This was taken as an indication that the overall fit might improve with the deletion of poorly fitting items. This proved to be true and reduction of the number of items consistentily improved the overall fit of the correlated four factor model to the data. Sixteen items (4 per factor) were chosen as a versatile number of items. The response burden was halved but there were enough items per factor to ensure adequate definition. An attempt to produce a 5 factor solution (the addition of $\mathrm{P}$ ) had to be abandoned when the MAP procedure (Velicer, 1976), Parallel Analysis (Horn, 1965) and (Lautenschlager, 1989) all recommended a 4 component solution. The 5th factor does appear in the cluster analysis as the profile Decision Making.

Once the refinement was complete, the 16 items chosen 
were confirmed on the confirmatory sample by running the correlated four factor model against the 6 other models. The correlated versions consistently showed better fit than the uncorrelated versions. Correlation of the stages is intuitive. The natural process of change can be envisioned as an upward curving spiral, generally linear but with room for lapses, recycling and renewed movement upward to change. For exercise this seems to be a particularly pertinent image. A lifetime commitment to regular exercise will always have times of lapse.

Using the three samples (Total, N=936; Sample 1, N=484; and Sample 2, N=415), a cluster analysis was then performed using the standardized scale scores of the 16 item version of the URICA-E. Nine clusters were chosen for interpretation. The exercise profiles did a credible job of mimicking McConnaughy and colleagues. A comparison of these exercise profiles with the profiles reported by McConnaughy et al. $(1983 ; 1989)$ on a clinic population show some differences and a number of similarities. The Maintenance cluster for exercise resembles what McConnaughy named Participation in her first study (McConnaughy, et al., 1983). The Action cluster for exercise bears a resemblance to McConnaughy's Participation profile in the second sample (McConnaughy, et al., 1989). The Decision Making cluster for exercise is very similar to the cluster of the same name in both papers. The Contemplation 1 cluster for exercise follows the pattern of McConnaughy's profile for the second 
sample also named Contemplation (McConnaughy, et al., 1989). There is no match for the contemplation 2 cluster for exercise. The Precontemplation 1 cluster for exercise most closely resembles McConnaughy's second sample Immotive profile (McConnaughy, et al., 1989). The Precontemplation 2 cluster for exercise echoes McConnaughy's second sample Precontemplation profile (McConnaughy, et al., 1989). The Precontemplation 3 cluster for exercise has no match. The Uninvolved cluster for exercise mimics McConnaughy's profiles of the same name for both samples (McConnaughy, et al., 1989, McConnaughy, et al., 1983).

The intriguing results were the multiple Precontemplation and Contemplation profiles. The most extreme (Precontemplation 3) profile did not have an equivalent in the clinical psychotherapy population. Perhaps it was due to the fact that McConnaughy's subjects were involved in therapy and therefore not the most extreme type of precontemplator. Whereas employees at a worksite smoking study could be the most intractable version of precontemplator for exercise. Precontemplation 2 is a less extreme version of Precontemplation. The PC scores are nearly the same for the two clusters and the $\mathrm{C}, \mathrm{A}$, and $\mathrm{M}$ scores of Precontemplation 2 are a standard deviation higher than that of Precontemplation 3. The Precontemplation 1 cluster has nearly the same PC scores as the other two Precontemplation clusters, its C scores are like Precontemplation 2 's but its $A$ and $M$ scores are a half of a 
standard deviation and a full standard deviation higher, respectively, then Precontemplation 2. The Contemplation 1 and the Contemplation 2 clusters are very similar except for the height of the M scores. M scores for Contemplation 2 are a half a standard deviation above the mean where they are a half of a standard deviation below the mean for Contemplation 1: Contemplation 2, as noted above, was only found in two of the four samples.

To summarize, the URICA-E replicated the work of McConnaughy, DiClemente, Prochaska, \& Velicer (1989) and McConnaughy, Prochaska, \& Velicer (1983) by producing the best fit of the data to a correlated four factor model. Refinement of the URICA-E to a 16 item instrument was necessary to produce a better fitting solution. This correlated four factor model was confirmed against 6 other models. Cluster Analysis, using the scale scores from the 16 item version of the URICA-E, produced 9 profiles that represented the four stages: PC (4 types), C (2 types), A (1 type), and $M$ ( 1 type), and, in addition, presented a Decision Making (preparation type) stage. The degree of similarity among the three samples was pronounced. Lastly, the congruity between the exercise profiles and the therapy derived samples of McConnaughy was not perfect, but it was considerable.

The differences in the naming of the profiles points out the need to validate, in some external way, the choice of name. Validation was attempted by matching the URICA-E 
profiles to the particular short form algorithm that had also been administered. The four short form algorithms will be investigated in study II and the validation of the URICA-E against one of them will be presented in study III. 


\section{Study II. An Evaluation of the Four Algorithms}

The purpose of study II is to evaluate the four discrete algorithms by examining both qualitative differences and similarities and quantitative differences and similarities. The qualitative examination looked at format and wording. Quantitative analysis investigated the ability of the each algorithm to classify the subjects into the same stage as the other algorithms.

Description of Staging Algorithms and Qualitative Analysis

Introduction. Three different formats were used for the four algorithms: a picture of 2 ladders (the Pladder), a series of questions with a 5 point Likert scale (the Pexscale and the Pexscpol and a series of questions using True or False (the Pproscal). The wording of the four algorithms was similar in the main and varied in part.

The Pladder. The first algorithm, the Pladder was modeled after a smoking algorithm (Biener \& Abrams, 1991). It consisted of a question above a drawing of 2 ladders side by side. The initial question was: "Now and in the past five years, have there been any times when you did regular exercise?" If you answered "Yes" you were asked to mark Ladder A and if you answered "No" you were asked to mark Ladder B. Ladder A and Ladder B each asked you to circle the number from 0 to 10 between the rungs that showed best where you are now. Five of the numbers had verbal descriptions attached to them. Appendix B presents a copy 
of the items. During primary data analysis, Ladder A was collapsed into 5 stages: PC, C, P, A, and M. Ladder B was collapsed into 3 stages: PC, C, and P. The members of the similar stages from the two ladders were then merged and a discrete stage was assigned to each participant.

Critique the pladder. The verbal descriptions given to the spaces between the rungs of ladder $A$ of the Pladder were identical to the Pexscale series of questions. Ladder B's verbal descriptions were unique to this algorithm. The intent of the Ladder's initial question, "Now and in the past five years, have there been any times when you did regular exercise?" was to discriminate relapsers from those who have been sedentary for five years. Ladder $B$ would then be answered only by the sedentary and Ladder A by a mixture of present and past exercisers. A problem with this format is the confusion that can be caused if the directions are not read carefully. A second difficulty lies in the visual layout of the ladders. For ladder $\mathrm{A}$ the verbal description for $\mathrm{M}$ is connected by a line to the number 10 which is sitting above the top rung of the ladder. The verbal description of $A$ is at the number 8 ; that of $P$, at the number 5 ; that of $\mathrm{C}$, at the number 2 ; and that of $\mathrm{PC}$, at the number 0 located below the bottom rung of the ladder. Ladder $B$ is similarly laid out with verbal descriptions at $10,8,5,2$, and 0 . The 10 represents $P$; the 8,5 and 2 represent $C$ and the $O$ represents PC. This gives a subject one way to be an $\mathrm{M}$ or an $\mathrm{A}$, two ways to be a $\mathrm{P}$ or $\mathrm{PC}$, and 
four ways to be a $C$. A third problem is that the definition of regular exercise only mentions frequency and duration but does not give examples of what constitutes exercise.

The Pexscale. The second algorithm was a series of 6 questions using a 5 point Likert scale (Strongly Disagree to Strongly Agree). Appendix $C$ includes a copy of the items. Question 1 represented PC; Question 2, C; Question 3, P; Question 4, A; Question 5, M; and Question 6, Relapse. The single question that a subject endorsed with Strongly Agree or Agree determined the subject's stage of change. Relapse was not conceptualized as a distinct stage. All subjects who endorsed Relapse also endorsed another stage. OnIy 7\% of the subjects could not be staged using this method (Marcus, Selby, Niaura \& Rossi, 1992).

The Pexscpo. The third algorithm, the Pexscpo, a series of 5 questions, was similar to the Pexscale except that no distinction was made between Action (A) and Maintenance (M). See Appendix D for an example. The original coding for the primary analysis shows the stages as PC, C, A, and M. The definition of Action (A) apparently has been refined over time, since the category that was classified in this procedure as Action (A) resembles what is now called Preparation (P). The present interpretation of this algorithm is that it is staging $\mathrm{PC}, \mathrm{C}, \mathrm{P}$, and $\mathrm{A} / \mathrm{M}$. Critique of the Pexscale and the Pexscpo. The pexscale and the Pexscpo are identical on the first three and the last question. The Pexscpo had a single question "I currently 
two questions which split A from $M$ dependent on the length of change (more or less than 6 months). The major problem with the Pexscpo and the Pexscale is the use of the 5-point Likert scale (Strongly Agree to Strongly Disagree). It made answering the questions more confusing rather than more precise. The questions were laid out as statements describing "how a person might feel about his or her exercise status". Each statement represented a stage of change. The subject was to assess how much they agreed or disagreed with the statements. The single statement, that a subject answered with agree or strongly agree, was assigned as the subject's stage of change. Seven percent could not be staged using this method. This seems a very roundabout way to find out if a person is performing the behavior of exercise or not, or if they are planning to do so in the future.

The Pproscal. The fourth algorithm, the Pproscal was a set of 5 questions that were answered by "True" or "False". This is the procedure that most closely resembles the algorithm employed for smoking. See Appendix E for the questions and the formula for scoring the algorithm. Each stage was determined by the answers to a combination of two of the questions, except in the case of Action (A) which was staged by the answer to a single question.

Critique of the Pproscal. The Pproscal differed in wording as well as format from the other algorithms. It was more similar to the wording and format used in smoking cessation. 
similar to the wording and format used in smoking cessation. This algorithm had a number of strengths. The Pproscal included a clear definition of regular exercise, its frequency and duration, and included examples of what would and would not be considered exercise. The questions were laid out as 5 simple statements, each representing a behavior or an intention. The "True" or "False" format was very easy and clear to answer. Before even looking at the quantitative results, the Pproscal would seem to be the algorithm of choice from a qualitative point of view. Quantitative Analysis of Staging Algorithms Introduction. Quantitative analysis investigated the ability of the each algorithm to classify the subjects into the same stage as the other algorithms. This was accomplished by examining the distributions by stage and cross tables of the algorithms against each other.

Method

Subjects. Within the context of a worksite smoking cessation study, the pladder was collected on all participants at all four of the worksites $(\mathrm{N}=936)$. The Pexscale was administered to only 3 of the worksites (the medical center, the retail store and the manufacturing firm) $(\mathrm{N}=484)$. The Pexscpo was collected only at one worksite (the post office) $(\mathrm{N}=415)$ and the Pproscal, was assessed at two of the worksites (the retail store and the manufacturing firm) (N=295).

Procedure. Analysis for the staging algorithms 
included both the previously presented qualitative assessment and the following quantitative appraisals. A comparison was made of the stage distributions frequencies (percentages) of the four algorithms. Then, assessment of the ability to classify into similar stage, was made by running cross tables of the pladder by the pexscale, the Pladder by the Pexscpo, the pladder by the Pproscal, and the Pexscale by the Pproscal.

\section{Results}

Quantitative Methods. A comparison was made of the stage distributions frequencies (percentages) of the 4 algorithms (see Table 5). Intuition would support the premise that more stable stages ( $P C \& M$ ) would show higher percentages of people than the more dynamic stages (C, P \& A) where subjects generally stay a shorter amount of time. A U shaped curve would graphically capture this image. Only one algorithm shows this expected U shaped curve, the Pproscal. 
Table 5

Stage Distribution Frequencies (percentages) of the 4 Algorithms

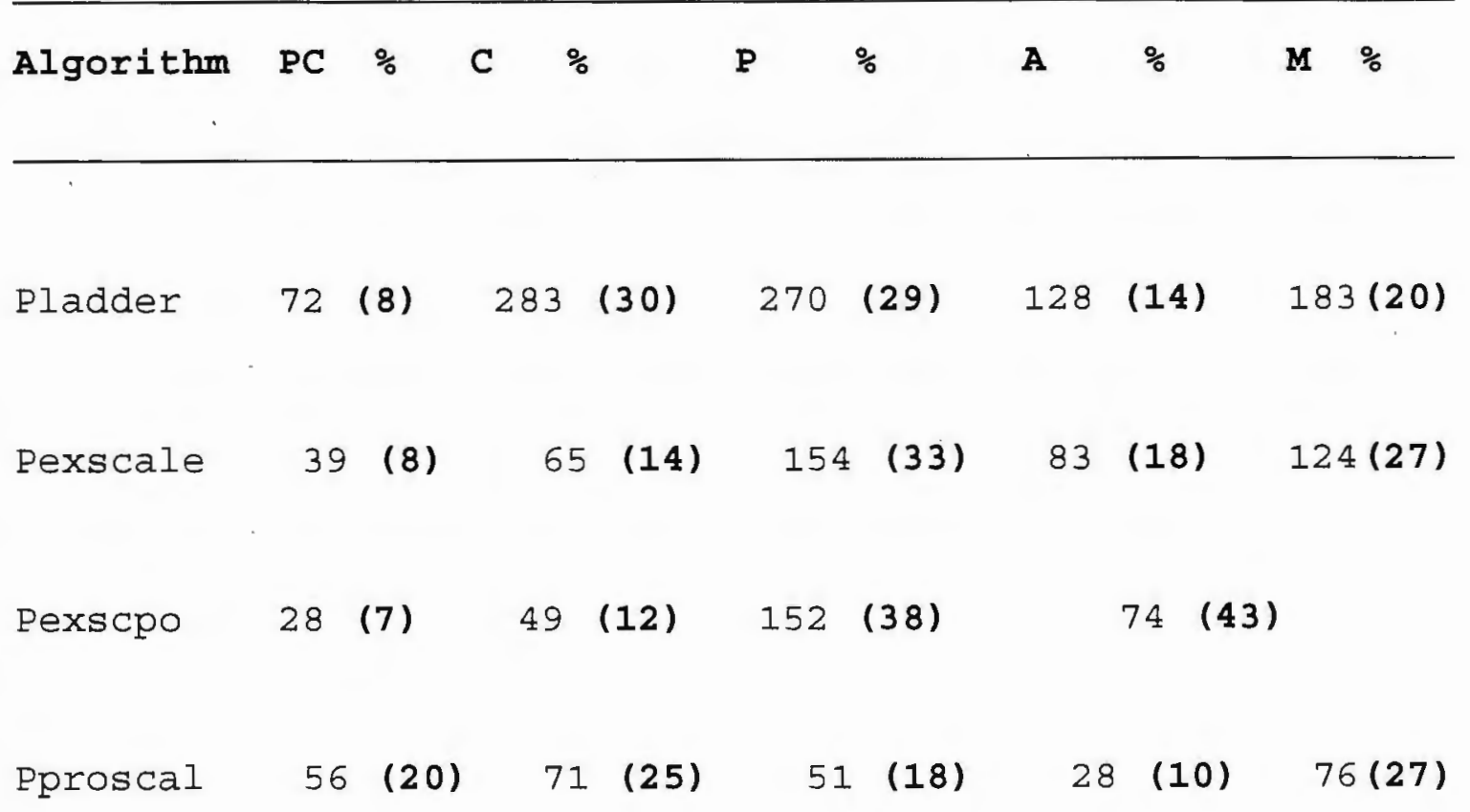


Cross tables of the Pladder by the Pexscale, the Pladder by the Pexscpo, the Pladder by the Pproscal, and the Pexscale by the Pproscal were run. The pladder and the Pexscpo placed subjects in the same stage an average of $67.8 \%$ of the time. Pladder and the pproscal, $65.0 \%$ of the time; Pexscale and the Pproscal, $61.6 \%$ of the time; and Pladder and the Pexscale, $56.4 \%$ of the time. See Tables 6 through 9. 
Table 6

Pladder by Pexscale Frequency Percentages

PEXSCALE

$\mathrm{N}$

PLADDER PC

C

$\mathrm{P}$

A

M

\subsection{3}

8.57

40.00

0

0

35

PC

$$
\begin{array}{llllll}
14.96 & 34.65 & 40.94 & 7.09 & 2.36 & 127
\end{array}
$$

C

$$
\begin{array}{llllll}
0.63 & 8.75 & 52.50 & 21.88 & 16.25 & 160
\end{array}
$$

$\mathrm{P}$
0
4.69
4.69
53.13
37.50
64

A

$\begin{array}{llllll}1.27 & 1.27 & 1.27 & 6.33 & 89.87 & 79\end{array}$

M 
Table 7

Pladder by Pexscpo Frequency Percentages

PEXSCPO

$\mathrm{N}$

\begin{tabular}{|c|c|c|c|c|c|}
\hline PLADDER & $\mathrm{PC}$ & C & $P$ & A & \\
\hline $\mathrm{PC}$ & 48.15 & 3.70 & 48.15 & 0 & 27 \\
\hline C & 13.16 & 31.58 & 50.00 & 5.26 & 114 \\
\hline $\mathrm{P}$ & 0 & 7.84 & 73.53 & 18.63 & 102 \\
\hline A & 0 & 5.00 & 5.00 & 90.00 & 60 \\
\hline M & 0 & 1.00 & 4.00 & 95.00 & 100 \\
\hline
\end{tabular}


Table 8

Pladder by Pproscal Frequency Percentages

PPROSCAL

$\mathrm{N}$

PLADDER PC

C

P

A

M

PC

95.65

4.35

0

0

0

23

C

30.11

52.69

12.90

1.08

3.23

93

P

6.59

21.98

42.86

13.19

15.38

91

A

0

2.56

0

35.90

61.54

39

M

0

0

0

2.78

97.22

36 
Table 9

Pexscale by Pproscal Frequency Percentages

PPROSCAL

$\begin{array}{lllll}\text { C } & \text { P } & \text { A } & \text { M }\end{array}$

PEXSCALE PC

$\mathrm{N}$

PC

84.62

11.54

0

0

3.85

26

C

10.26

64.10

10.26

7.69

7.69

39

P

21.35

32.58

38.20

2.25

5.62

89

A

2.13

12.77

12.77

40.43

31.91

47

M

0

3.13

9.38

6.25

81.25

64 
Discussion

An examination of the stage distribution percentages is illuminating: it shows a definite similarity of results between the Pexscale and the Pexscpo. Qualitatively, these two algorithms were identical in wording and format and only differed in their differentiation of $\mathrm{A}$ from $\mathrm{M}$. They both suffered from the use of a Likert scale (Strongly Agree to Strongly Disagree) to answer statements about "how a person might feel about his or her exercise status". The pladder, on the other hand, categorized twice as many subjects to be in $C$ and $3 / 4$ as many each in $A$ and $M$ and the same amount in $P C$ and $P$ as did Pexscale and Pexscpo. Qualitatively, the Pladder suffers from its incomplete definition of exercise, the unequal staging possibilities, and its layout. The most obvious difference is seen in the Pproscal. Three times as many subjects are categorized as PC, two times as many in C, half as many in $P$, half as many in $A$ and the same amount in $M$ as with the Pexscale and the Pexscpo. Qualitatively, the Pproscal clearly had the greatest number of strengths, in particular, the use of 5 clear statements easily answered by a True or a False.

Within the Transtheoretical Model, Precontemplation and Maintenance are thought of as being the more stable stages where people remain for long periods of time. In Precontemplation, there is no intention to change within the 
next 6 months. In Maintenance, change was accomplished more than 6 months ago. Contemplation, Preparation, and Action are considered the dynamic stages. You can only be in Action for 6 months at the most before you enter Maintenance. The other way to leave Action is to relapse back into an earlier stage. Preparation and Contemplation both depict intention within a specified time limit. Theoretically, this would translate to a stage distribution which was larger for $P C$ and $M$ than it was for $C, P, \& M$. This is the type distribution found in the Pproscal algorithm.

Another staging algorithm, which is showing stage distribution similar to the Pproscal, is a single question algorithm. Data has been gathered using this single question format by using an instrument of the Cancer Prevention Research Center called the General Health Survey. The General Health Survey (See Appendix F) stages ten behaviors, including exercise. A random selection of 1,884 Rhode Islanders and 13,930 members of Harvard Community Health Program answered the General Health Survey. The I,884 Rhode Islanders had a frequency percentage distributions of PC (19) C (13) P (19) A (7) M (42) for the exercise question. The Harvard Community Health Plan members produced stage distributions of PC (18) C (14) P (18) A (11) M (39) on the exercise question. As reported previously, the pproscal showed a frequency distribution of: PC (20) C (25) P (18) A (10) M (27). It should be noted 
that the single question format does not include a behavioral component in the definition of $P$, only the intention of starting to exercise with in the next 30 days. As can be seen above, the single question format is not unlike the Pproscal. Because of the qualitative superiority and the similarity of distribution with the single question, the Pproscal was chosen as the discrete algorithm to use in Study III where its relationship with the continuous measure of change, the URICA-E will be studied. 


\section{Study III. Relationship between URICA-E and Algorithms}

The URICA-E is a staging instrument adapted for exercise behavior and based on the University of Rhode Island Change Assessment (URICA) (McConnaughy, DiClemente, Prochaska, \& Velicer, 1989; McConnaughy, Prochaska, \& Velicer, 1983). It is a short 31 item inventory which yields four scales that represent the stages of change (PC, C, A, \& M). In Study I, the instrument was replicated and refined down to 16 items (4 per stage). Scale scores were then formed by calculating the unweighted sum of the scores on the 4 items allocated to each stage then dividing the total by 4 . This score was standardized to a T-score metric (mean of 50 and a standard deviation of 10). Each subject therefore had 4 standardized T-scores, one for each stage. These standardized scale scores were then used to cluster the subjects and generate profiles of subtypes of changers.

In Study II, four discrete algorithms for staging exercise behavior were compared qualitatively and quantitatively by examining stage distribution. One of the algorithms, the Pproscal, proved to be superior. It had the most inclusive definition of exercise. It was clear and easy to answer, requiring only a True or False response. Lastly, the Pproscal produced a much higher distribution for PC. This concurred with both pilot data on 1,844 Rhode Islanders and with data gathered on 13,930 members of Harvard Community Health Plan using a single question version for staging exercise behavior. 
In Study III, there will be a comparison of the short form algorithm, Pproscal, and the continuous measure, the URICA-E. Two techniques will be used. The first will employ the cluster profiles generated from the standardized scale scores of the 16 item version of the URICA-E. These profiles will be cross classified with the discrete algorithm, the Pproscal. The second technique will be discriminant function analysis. Discriminant function analysis will be done twice, first using the 31 items of the URICA-E, and then again, using the 4 scale scores from the 16 item version. Discriminant function analysis tests the ability of the items or the scale scores of the URICA-E to predict membership in the discrete stage of the Pproscal. Discriminant function is a way to quantify the principles of human decision making (Norusis, 1990). With information from a set of cases for which you know the outcome, equations can be derived to separate the cases into groups. In discriminant analysis, coefficients are selected so that the scores are similar within a group but differ as much as possible among groups. The actual group membership is known and the probable group membership is calculated based on the discriminant analysis. The maximum number of significant discriminant functions is either one fewer than the number of groups or equal to the number of predictor variables, which ever is smaller. The first discriminant function always makes the clearest separations, with each succeeding, orthogonal functions becoming successively less important in 
classification. Significance tests indicate which functions discriminate among groups and which provide no additional information.

The adequacy of classification is depicted in the classification table. The strength of association between group membership (the Pproscal) and the predictor variables (the URICA-E scores) can be interpreted through the canonical correlation. For each discriminant function (canonical variable) a canonical correlation is found that, when squared, indicates the proportion of variance shared between grouping variables (the Pproscal) and predictor variables (URICA-E scores) on that dimension. Another tool in the interpretation of discriminant function is the plot of group centroids on all significant discriminant functions. Centroids are the means of the groups on each of the derived new variables (canonical variables) created as a weighted linear composite of the observed variables.

\section{Method}

Subjects. The sample $(\mathrm{N}=295)$ that was compared was grouped and named after the short form algorithm (the Pproscal) administered to them in addition to the URICA-E.

Procedure. Using the URICA-E profiles from the cluster analysis, a classification matrix was generated to discover if the Pproscal algorithm classified subjects into the same stages as the URICA-E profiles. Agreement was determined by 
examining the percentage correct in the cross classification matrix and looking at the off diagonal pattern for disagreement.

Discriminant function analysis then used the 31 items of the URICA-E as predictor variables and the stages of the Pproscal as the criterion groups. The analysis focused on the classification tables, the canonical correlations, the percentage of variance shared, and the group centroids. This analysis permitted an examination of the precision with which the Pproscal classified subjects into the same stages as the URICA-E.

Discriminant function analysis also used the four scale scores of the reduced 16 item URICA-E as the predictor variables and the algorithm stages as the criterion groups. The analysis focused on the classification tables, the canonical correlations, the percentage of variance shared, and the group centroids. This analysis again allowed a comparison of how precisely the Pproscal classified subjects into the same stages as the URICA-E.

Results

Comparison of Profiles of URICA-E and Pproscal.

The cross classification matrix (see Table 10) revealed that the Maintenance profile had $67 \%$ correct classification when compared with the pproscal stage $\underline{M}$. It also had a 33\% misclassification with PC. This is basically correct classification, but a problem between PC and M appears. The Action profile had a $67 \%$ misclassification with 
Pproscal stage $M$ and a 33\% misclassification with PC. This profile is clearly not picking up the same staging criteria as the Pproscal.

The Decision Making profile had $32 \%$ correct classification when compared with Pproscal stage $\underline{\underline{P}}$ and $30 \%$ with $\underline{C}$. Although there is some misclassification with $A$ and M this profile is mainly in agreement.

The Contemplation 1 profile is ambiguous. It had a 36\% misclassification with Pproscal stage PC, but a $33 \%$ correct classification with C. PC and C are such different stages that this is a real problem for this profile.

The Contemplation 2 profile had a 56\% misclassification with Pproscal stage $M$. The could be viewed as an endorsement for the interpretation of this profile as representing maintenance people who are in temporary lapse.

The Precontemplation 1 profile had correct classification of $28 \%$ with Pproscal PC, but a $38 \%$ misclassification with stage C, and a $26 \%$ misclassification with $P$. This is a problem when $P C$ is confused with $C$ and $P$. The Precontemplation 2 profile had a $56 \%$ correct classification when compared with the Pproscal stage PC. This profile is capturing the same elements as Pproscal's PC stage.

The Precontemplation 3 profile had a $44 \%$ misclassification with Pproscal stage $C$ and a $24 \%$ misclassification with $M$. This profile and the Pproscal are getting very different responses. Again note the confusion 
between $\mathrm{PC}$ and $\mathrm{M}$.

The Uninvolved profile classifies with 29\% with Pproscal stage $C, 26 \%$ with $P, 23 \%$ with $A$ and $19 \%$ with $M$, and only $3 \%$ with PC. This concurs with the profile which has all scores hovering near the mean.

Another way to examine the results comparing the profiles of the URICA-E and the Pproscal would be to assess how well the Pproscal agreed with the names for the profiles. To summarize: Pproscal agreed with the labels for Maintenance, Decision Making, and Precontemplation 2 . It confused Action with $\mathrm{M}$ which is a problem of degree, not kind. Contemplation 2 being seen as $M$ is probably a correct interpretation of the profile as representing committed exercisers in temporary lapse. Precontemplation 1, Precontemplation 3 , and Uninvolved all represent disagreement with the majority. In each case the majority are classified as $C$ by the Pproscal.

The confusion between PC and M, two very disparate stages, may be due to the fact that, in a general population, some subjects may not self define themselves as having the problem behavior, a necessary condition for accurate interpretation of the URICA-E items. A person may assume that their current level of exercise is adequate, i.e., walking on a job, while it is not, other people may exercise at rates exceeding established standards but wish to achieve a much higher personal level.

The profiles did a credible job of replicating 
McConnaughy's $(1983,1989)$ work, but the attempt at validation against the Pproscal algorithm produced very mixed results. The conclusion is that the URICA-E is not just an alternative staging algorithm, but is something more complex. 
Table 10

Comparison of URICA-E Profiles by Stages of the Pproscal

Pproscal

Profile

PC

$\mathrm{C}$

P

A

M

Maint

$33 \%$

0

0

0

$67 \%$

Action

$33 \%$

0

0

0

$67 \%$

Dec Mak

0

$30 \%$

$32 \%$

$18 \%$

$21 \%$

Cont 1

$36 \%$

$33 \%$

$6 \%$

6\%

$18 \%$

Cont 2

$11 \%$

0

0

$33 \%$

$56 \%$

PC 1

$28 \%$

$38 \%$

$26 \%$

$2 \%$

$6 \%$

PC 2

$56 \%$

$7 \%$

$7 \%$

$4 \%$

$26 \%$

PC 3

0

$44 \%$

$20 \%$

$12 \%$

$24 \%$

Uninv 1

$3 \%$

$29 \%$

$26 \%$

$23 \%$

$19 \%$ 
Comparison of URICA-E (31 Items) and Pproscal

The discriminant function correctly classified $65.42 \%$ of the subjects. Table 11 presents the cross-classification table. It should be noted that the largest percent of misclassification is found in stages that are adjacent and somewhat correlated to the correctly classified stage. The chance level of prediction for a five group discriminant function is 20\%, so the 31 items did more than 3 times as well (65.42\%) at predicting group membership correctly. All four functions were found to be significantly different from each other. 
Table 11

Discriminant Function Analysis: Pproscal as group and

31 Items of URICA-E as predictors

Classification Results

ACTUAL $\div$ OF PERCENT PREDICTED GROUP MEMBERSHIP

$\begin{array}{lllllllll}\text { GROUP } & \text { CASES } & \text { PC } & \text { C } & \text { P } & \text { A } & \text { M }\end{array}$

\begin{tabular}{lllllll}
\hline PreCont & 21 & 82 & 13 & 3 & 2 & 0 \\
Contemp & 25 & 5 & 63 & 16 & 12 & 4 \\
Prep & 18 & 10 & 17 & 60 & 12 & 2 \\
Action & 10 & 7 & 13 & 20 & 50 & 10 \\
Maint & 26 & 4 & 4 & 7 & 21 & 65 \\
\hline
\end{tabular}


Function 1. The canonical correlation for Function 1 was .72 $(p<.01)$ and the percentage of variance accounted for was $52 \%$. Figure 11 contains a plot of the group centroids for Function 1 by Function 2 using 31 Items. Function 1 separates all 5 groups in a linear fashion (PC=-1.52, C=.47, $\mathrm{P}=0, \mathrm{~A}=.90$, and $\mathrm{M}=1.31$ ). The ordering for the stages follows the ordering specified by the theory. 
Figure 11 PPROSCAL (31 Items) GROUP CENTROIDS Function 1 by

Function 2

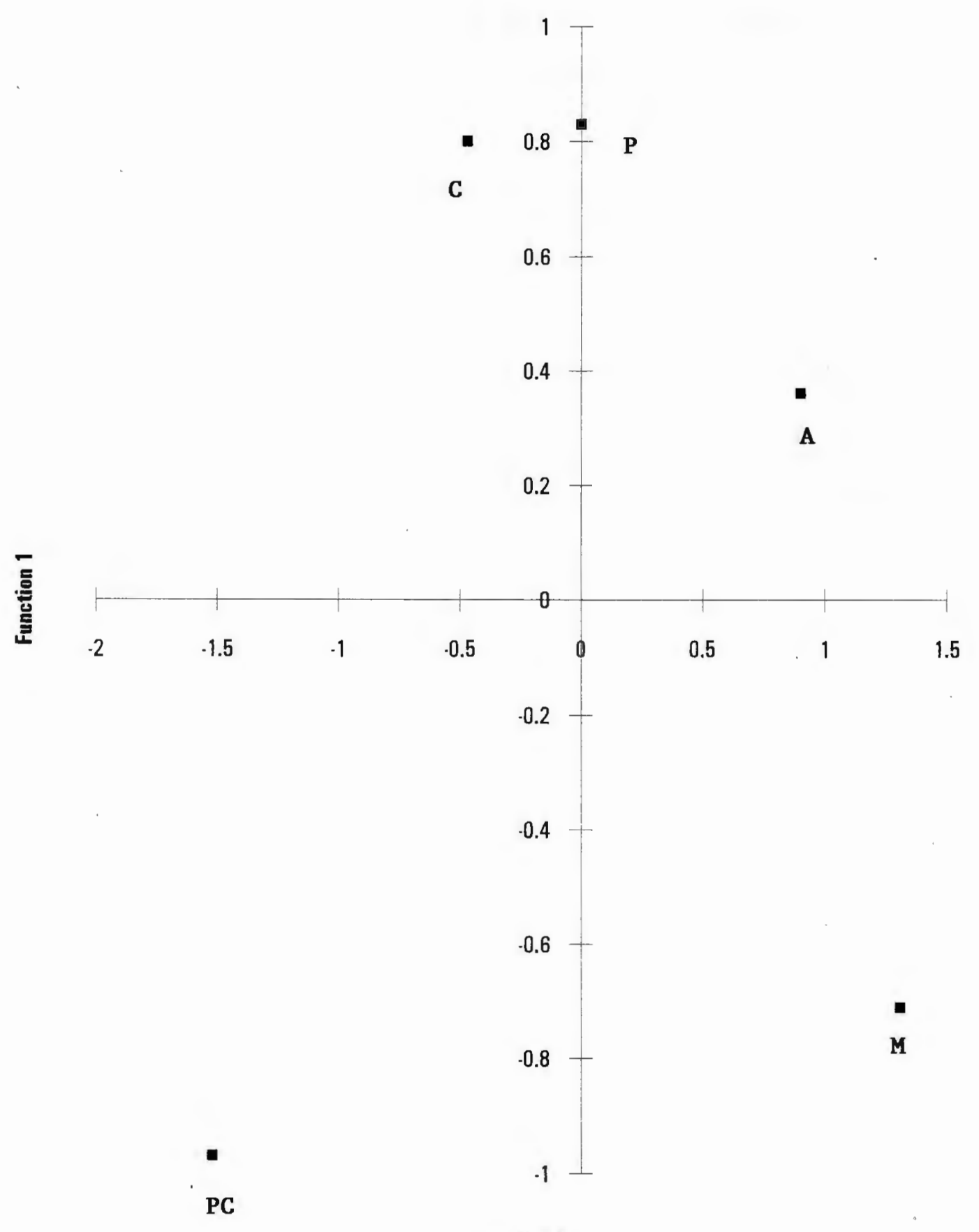

Function 2 
Function 2. For Function 2, the Canonical Correlation was $.62(\mathrm{p}<.01)$ and the percentage of variance accounted for was $38 \%$. Function 2 separates the static groups where there is little movement ( $\mathrm{PC} \& \mathrm{M}$ ) from the dynamic groups, that is stages that people often only stay in for a short time (C, $P, \& A)$.

Function 3. The canonical correlation for Function 3 was $.38(\mathrm{p}<.01)$ and the percentage of variance shared was $14 \%$ See Figure 12 for a plot of Function 2 by Function 3. Function 3 primarily separates Preparation from Action. Function 4. For Function 4, the Canonical Correlation was $.35(\mathrm{p}<.01)$ and the percentage of variance shared was $12 \%$ This function only involved a small incremental contribution and was, therefore, difficult to interpret. 


\section{Group Centroids}

Fig. 12 Pproscal (31 Items) Function 2 by Function 3

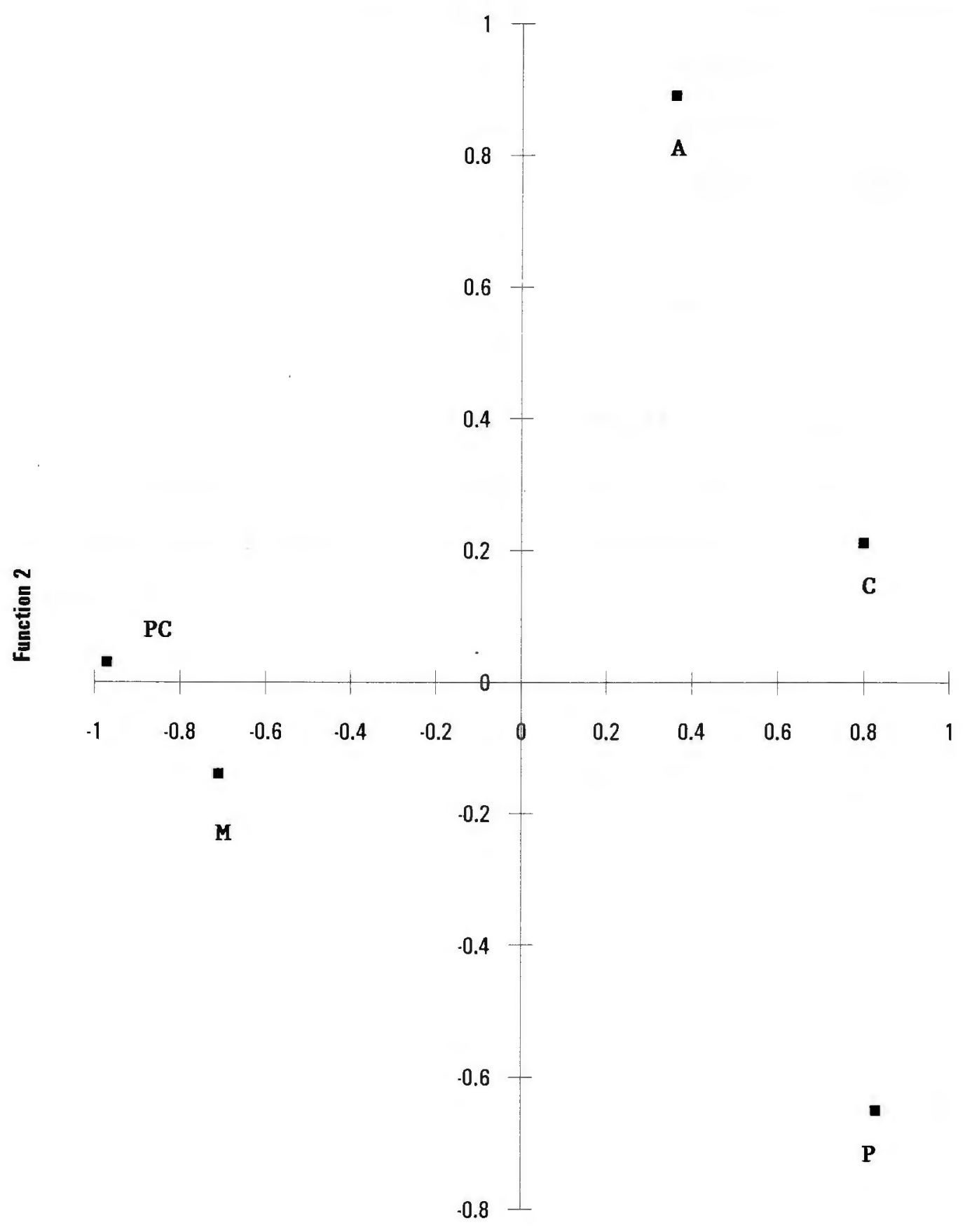

Function 3 
Comparison of URICA-E (16 items) and Pproscal

The discriminant function correctly classified $49.83 \%$ of the subjects. Table 12 presents the cross-classification table. The percent predicted group membership for all the stages is larger for the stage it corresponds with than for off stages. There is again seen some confusion of classification with adjacent, correlated stages. Again the problem of confusion between Maintenance and Precontemplation is seen. The chance level of prediction for a five group discriminant function is $20 \%$, so the 16 items was almost two and a half times better at predicting group membership correctly than chance. Only two of the four functions were found to be significant. 
Table 12

Discriminant Function Analysis: Pproscal as group and 16 Items of URICA-E as predictors

Classification Results

ACTUAL : OF PERCENT PREDICTED GROUP MEMBERSHIP

$\begin{array}{lllllll}\text { GROUP } & \text { CASES } & \text { PC } & \text { C } & \text { P } & \text { A } & \text { M }\end{array}$

\begin{tabular}{lllllll}
\hline PC & 21 & 48 & 15 & 5 & 3 & 30 \\
C & 25 & 12 & 47 & 21 & 16 & 4 \\
P & 18 & 8 & 14 & 58 & 21 & 0 \\
A & 10 & 3 & 13 & 17 & 47 & 20 \\
M & 26 & 17 & 8 & 7 & 18 & 51
\end{tabular}


Function 1. Function 1 had a canonical correlation of .61 $(\mathrm{p}<.01)$ and the percentage of variance accounted for was $37 \%$. A plot of the group centroids can be seen in Figure 13. For the 16 items, Function 1 separates the static stages ( $M \& P C)$ from the dynamic stages $(A, P, \& C)$.

Function 2. Function 2 had a canonical correlation of $.44(\mathrm{p}<.01)$ and the percentage of variance accounted for was $19 \%$. As seen on the plot of centroids for the scale scores, Function 2 primarily separates the group which exercises (A) from the group which does not exercise (PC). Function 3 and Function 4 were not significant. 


\section{Group Centroids}

Fig. 13 Pproscal (16 Items) Function 1 by Function 2

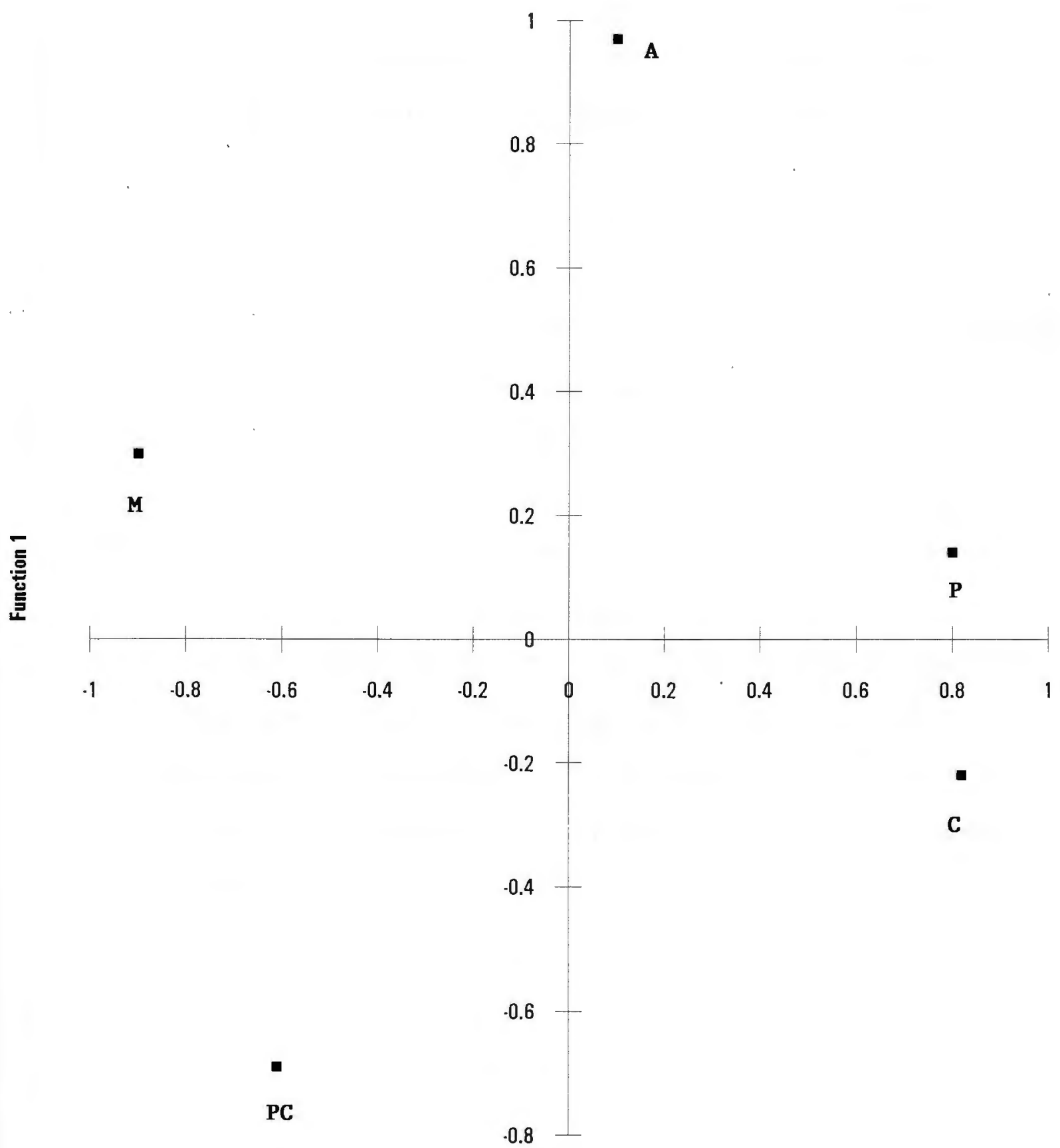

Function 2 
Comparison of URICA-E (scale scores) and Pproscal

The discriminant function correctly classified $42.37 \%$ of the subjects. Table 13 presents the cross-classification table. The percent predicted group membership for PC, C, A, $\& M$ is larger for the stage it corresponds with than for off stages. As can be seen, the majority of those whose actual group is Preparation, do not get classified as $\mathrm{P}$ for their predicted group. This is probably explained by the fact that the URICA-E has no Preparation stage. There is again seen some confusion of classification with adjacent stages. Again the problem of confusion between Maintenance and Precontemplation is seen for both these groups. The chance level of prediction for a five group discriminant function is $20 \%$, so the 4 scale scores did more than twice as well (42.37\%) at predicting group membership correctly. The lower values produced by the scale scores underlines the fact that some of the items that were deleted from the 31 were accounting for some of the variance. Only two of the four functions were found to be significantly different from each other. 
Table 13

Discriminant Function Analysis: Pproscal as group and 4 Scale Scores of URICA-E as predictors Classification Results

ACTUAL NO PERCENT PREDICTED GROUP MEMBERSHIP $\begin{array}{llllllll}\text { GROUP CASES } & \text { PC } & \text { C } & \text { P } & \text { A } & \text { M }\end{array}$

\begin{tabular}{lllllll}
\hline PC & 61 & 44 & 16 & 7 & 2 & 31 \\
C & 75 & 8 & 49 & 15 & 20 & 8 \\
P & 52 & 12 & 40 & 21 & 23 & 4 \\
A & 30 & 3 & 17 & 10 & 47 & 23 \\
M & 77 & 20 & 3 & 5 & 26 & 47 \\
\hline
\end{tabular}


Function 1. Function 1 had a canonical correlation of .56 $(p<.01$ ) with a percentage of variance accounted for of $31 \%$. A plot of the group centroids can be seen in Figure 14. For the scale scores, Function 1 separates the static stages (M $\&$ PC) from the dynamic stages (A, P, \& C).

Function 2. Function 2 had a Canonical Correlation of $.39(p<.01)$ and the percentage of variance accounted for was $15 \%$. As seen on the plot of centroids for the scale scores, Function 2 primarily separates the group which exercises (A) from the group which does not exercise (PC). Function 3 and Function 4 were not significant. 


\section{Group Centroids}

Fig. 14 Pproscal (Scale Scores) Function 1 by Function 2

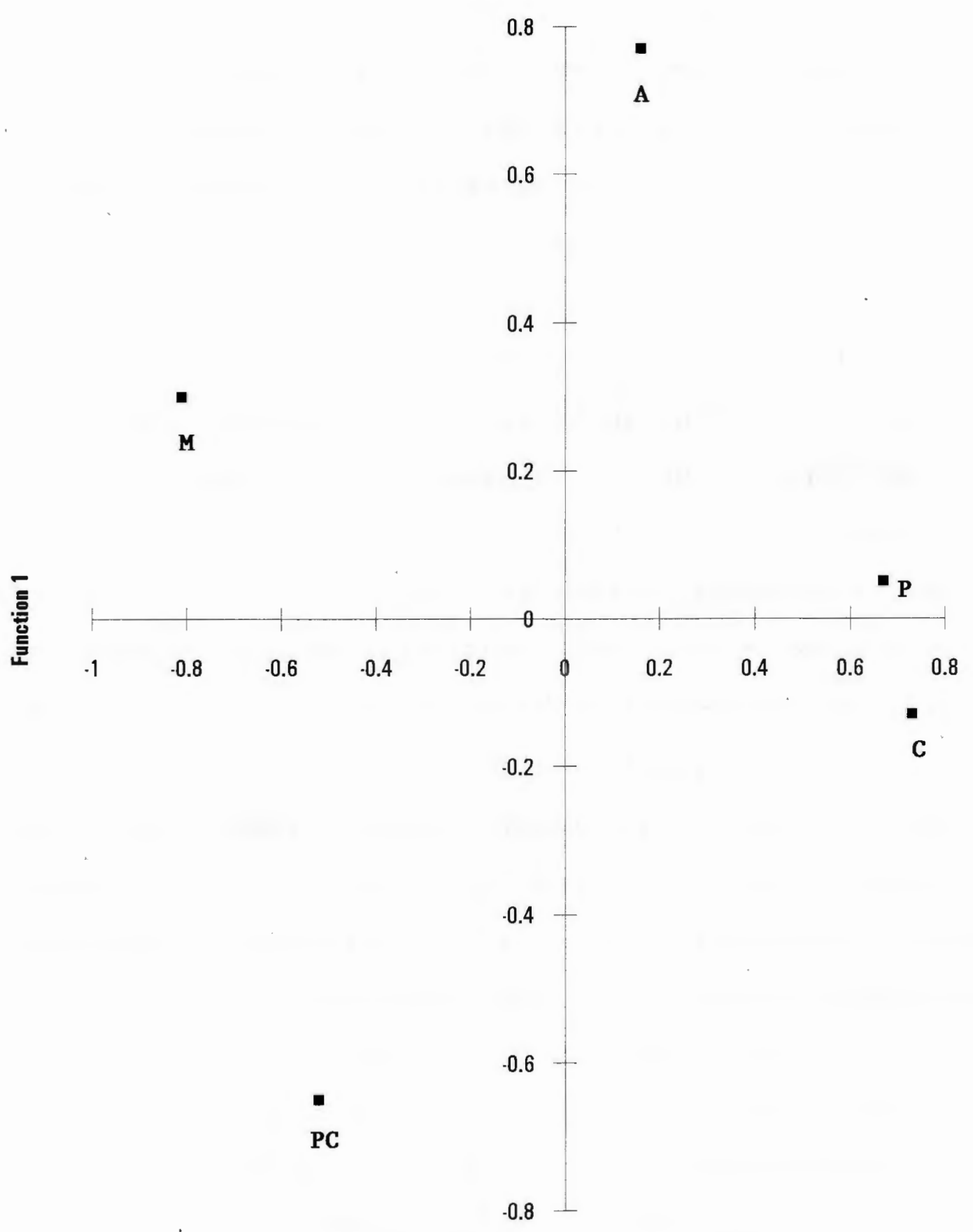

Function 2 
Since differences were noted between the item results and the scale scores results, adjustment for the differences in the number of variables was calculated by adjusting the canonical correlations for the functions by use of a shrinkage formula for $R$ squared (Kerlinger \& Pedhazur, 1973). Adjustment using the shrinkage formula resulted in a very small change in the differences between the item results and the scale score results.

Discussion

To summarize Study III, there was substantial disagreement between classification by the profiles of the URICA-E and the discrete stages of the short algorithm, Pproscal. It is concluded that the continuous measure of stage of change, the URICA-E, is substantially different and more complex than the algorithm. The discriminant function, using the 31 items, was able to clearly separate all 5 stages on Function 1 . On Function 2 for the 31 items, static stages separated from dynamic ones. The 16 items and the scale scores, on the other hand, did a poorer job at delineating all five stages. For the 16 items and the scale scores, Function 1 separated static states from dynamic ones and Function 2, exercise from no exercise. Three of the four PC items could easily be endorsed by M people who did not feel they had a problem with their exercise habits and had no intention of changing. This confusion between PC and M permeates the analyses. 
Overall Discussion

Staging is an important dimension of the Transtheoretical Model of Behavior Change and until now, no comparison had been made of the different methods used for staging. The URICA-E, a staging instrument adapted for exercise behavior and based on the University of Rhode Island Change Assessment (URICA) (MCConnaughy, DiClemente, Prochaska, \& Velicer, 1989; McConnaughy, Prochaska, \& Velicer, 1983) yielded four scales that represented the stages of change (PC, C, A, \& M). In Study $I$, the instrument was refined down to 16 items (4 per stage) and confirmatory factor analysis, using a correlated four factor model showed a better fit to the data then the original 31 items. Using standardized scale scores from the 16 item version of the URICA-E, 9 subtypes of changers were discovered using cluster analysis.

In Study II, four discrete algorithms for staging exercise behavior were compared qualitatively and quantitatively by examining stage distribution. One of the algorithms, the Pproscal, proved to be superior. It had the most inclusive definition of exercise. It was clear and easy to answer, requiring only a True or False response. Lastly, the Pproscal produced a much higher distribution for PC. This concurred with both pilot data on 1,844 Rhode Islanders and with data from 13,930 members of Harvard Community Health Plan using a single question version for 
staging exercise behavior.

In Study III, there was a comparison of the short form algorithm, Pproscal, and the continuous measure, the URICAE. Two techniques were used. The first was a comparison of the cluster profiles and the Pproscal. The profiles of the URICA-E had limited success at cross classifying the discrete stages of the short algorithm, Pproscal, leading to the belief that the continuous measure of stage of change, the URICA-E, is different and more complex than the algorithm.

The second technique was discriminant function analysis for both the 31 items, 16 items, and the 4 scale scores of the URICA-E. The discriminant function, using the 31 items, was able to clearly separate all 5 stages on Function 1 . On Function 2 for the 31 items, static stages separated from dynamic ones. The 16 items and the scale scores, on the other hand, did a poorer job at delineating all five stages. For the 16 items and the scale scores, Function 1 separated static states from dynamic ones and Function 2, exercise from no exercise. The percentage of concurrence was far higher for the 31 items than for the 16 items or the 4 scale scores.

The research questions that this study attempted to ask are:

\section{1) Do the algorithms stage subjects in a similar way?}

The different algorithms did not stage subjects in exactly the same way. 


\section{2) Do different formats and wording of algorithms change a subject's choice of stage?}

The answer to this is yes. The algorithms (Pexscale \& Pexscpo), that had similar format and wording, produced the most similar stage percentages. The Pproscal, which had the True/False format, produced stage percentages much more similar to the single question format used in a General Health Survey administered by the Cancer Prevention Research Center to a random selection of Rhode Islanders. A comparison of the single question format to the four algorithms used in this study shows a greater concurrence with the Pproscal stage percentages.

3) Does an algorithm (the Pproscal) stage a subject the same way as a continuous measure?

There was a difference in the way the Pproscal staged subjects and the way the URICA-E staged them. The continuous measure seems to be something different than a discrete algorithm.

\section{4) Can richer information be obtained from a continuous measure?}

It is intuitive that a profile which provides data on all four stages of a subject has richer information than a discrete algorithm that consigns a subject to a single stage. The problem is to how to interpret the multifaceted profiles. The profiles did not show close agreement when compared to the algorithms. When examining the group centroids it was found that $P C$ was difficult to distinguish 
from $M$ stage. It became obvious that $P C$ and $M$ can become confused in a general population where some subjects have the problem behavior and some do not. The original instrument had been written for a clinical population where all subjects had admitted the problem behavior. In the general population, a Maintenance person who exercises regularly and plans to make no changes comes out looking like a Precontemplation person who does not exercise and also does not plan to change.

A second problem is the naming of profiles. Outside validation with another instrument such as the Pros and Cons Scale, Temptation Scale, Self-efficacy Scale or Processes of Change Scale of the Transtheroretical Model should be attempted to answer questions such as are the three Precontemplation profiles really different. Other measures of the problem behavior would also provide external validity. For example, minutes of vigorous exercise done a week could verify stage of change. If there are three types of PC people, different types of interventions could be more effective for the different groups.

\section{5) Is the response burden of answering 32 questions too}

\section{great?}

The obvious answer is that 936 people answered the questionnaire so it isn't too great, but the reduced number of items produced a better fit of the data to a correlated four factor model. However, the reduced item set was not as accurate in classifying people. 
This study hoped to give some pointers on the virtues and drawbacks of the two methods of staging so that researchers can know what they can expect from the tool they choose to use for staging. To summarize: (1) only use the long form, as it is currently written, with clinical populations that all have the problem behavior in order to be able to differentiate between PC and $\mathrm{M}_{i}$ (2) use the continuous form if you wish to be able to investigate the profiles of sub-types of changers by clustering the subjects; (3) profiles should be further validated with outside instruments (i.e. Pros \& Cons, Temptations, or Processes of Change of the Transtheoretical Model) to see if there are real differences between similar types; (4) the Pproscal algorithm produces a very different stage distribution than the other algorithms and does a better job of staging subjects into Precontemplation. Its distributions are also more similar to a single question format.

Recommendations for future research would be (1) administer the URICA-E and two algorithms (Pproscal and Single Question); (2) to rewrite the Precontemplation items of the URICA-E so that they could not be endorsed by Maintenance people; (3) to write at least 8 Preparation items for the URICA-E, trying to capture both intention and behavior; (4) to develop 5 scale scores on which the subjects would be clustered; (5) to validate the profiles on outside constructs like the Pros and Cons, the Temptations 
or the Processes of Change of the Transtheoretical Model, and (6) to compare these 5 scale scores to both the Pproscal and the single question discrete staging algorithm. A short form algorithm has all the virtues of parsimony but you can't beat the continuous measure for richness and depth. 


\section{Appendix Stages of Changequesianaire \\ Precoritemplation}

Item:

(T) As far as I'm concerned, I don't have any problems that neod changing.

(5. I'm not the problem one. It doesn't make sense for me to be here.

15. Being here is pretty much of a waste of time for me because the problem doesn't have to do with me.

(13) I guess I have faults, but there's noching that I really need to change.

23. I may be part of the problem. but I don't really think I am.

26. All this talk about psychology is boring. Why can't people just forget about their problems?

29. I have worries but so does the next person. Why spend time thinking about them?

31. I would rather cope with my faults than try to change them.

\section{Contemplation}

Item:

(2i I think I might be ready for some self-improvement.

(4. It might be worthwhile to work on my problem.

(\&: I've been thinking that I might want to change something about myself.

12. I'm hoping this place will help me to better understand myself.

(15) I have a problem and I really think I should work on it.

19. I wish I had more ideas on how to solve my problem.

21. Maybe this place will be able to help me.

24. I hope that someone here will have some good advice for me.

Action

Item:

3. I am doing something about the problems that had been bothering me.

7. I am finally doing some work on my problems.

10. At times my problem is difficult, but I'm working on it.

(14. I am really working hard to change.

(17) Even though I'm not always sucoessful in changing, I am at least working on my problem.

20. I have startod working on my problems but I would like help.

25. Anyone can talk about changing; I'm actually doing something about it.

30. I am actively working on my problem.

\section{Märienance}

Item:

(6) It worries me that $\mathrm{I}$ might slip back on a problem I have alieady changed, so I am here to scek help.

9. I have becen sucoessful in wodaing on my problem but $\Gamma m$ nol sure I can keep up the effort on my own.

16. I'm not following through with what I had already changed as well as I had boped, and I'm here to prevent a relapse of the problem.

18. I thought once I had resolved the problem I would be free of it, but sometimes I still find myself striggling with it

(22) I may need a boost right now to help me maintain the changes I've already made.

27. I'm here to prevent mysclf from having a relapse of my problem.

28. It is frustrating, but I feel I might be having a recurrence of a problem I thought I had resolved.

- (52) After all I bad done to try to change my problem, every now and again it comes back to haunt me. 


\section{APPENDIX B THE PLADDER}

Please let us know about what exercise you do and what your atuitude about exercise is. A lot of people do not participate in much exercise, and would like to participace in more. Your frank and careful answers will hclp us co undcrstand what might be done about this.

Now, and in the past five years, have there been any times al all when you did Iegulacexercise?* Plcase chock YES or NO:

\section{$\square$ Yes}

If YES, circle the number on LADDER A that best shows where you are now. Each rung on this ladder shows where various people are in their thinking about exencising.

\section{LADDER A}

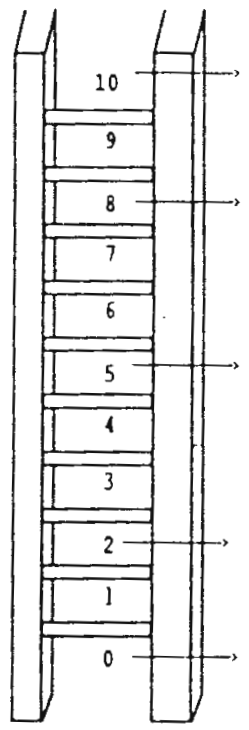

1 currenliy exercise regularity" mo have done so for longer than 6 months

1 cirrently exercise regulariy" but I have only begen woing so within the tast 6 months

I currentiy exercise some, out not regulary"

1 currently oo not exercise, but exersise in ine next 6 monts.

1 currentiy to not exercise and 1 co not iniend to start exerctsing in the next 6 montrs. I an thinkting wour starting to

\section{No}

If NO. circle the number on LADDER B that best shows where you arc now. Each nung on this ladder shows where various people are in their thinking about excrcising.

\section{LADDER B}

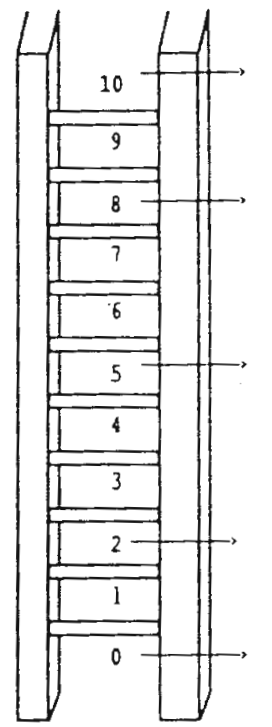

- Regular exercise $=3$ times or more per week, for 20 minutes or longer. 


\section{APPENDIX C THE PEXSCALE}

Please indicate how much you agree or disagree with each statement. Think about how you feel right now, not how you have felt in the past or would like to feel.

Please circle the number that best represents your answer. (Regular exercise $=3$ times or more per week for 15 minutes or longer.)

1. I currently do not exercise and I do not intend to stan exercising in the next 6 months.

$\begin{array}{ccccc}1 & 2 & 3 & 4 & 5 \\ \text { Surongly } & \text { Diragree } & \text { Undecided } & \text { Agree } & \begin{array}{c}\text { Surongly } \\ \text { Disagree }\end{array}\end{array}$

2. I currently do not excrcise, but I am thinking about staring to exercise in the next 6 months.
Surongly
Disagree
$\begin{array}{ccc}2 & 3 & 4 \\ \text { Disagree } & \text { lindecided } & \text { Agrue }\end{array}$
5
Surongly
Agree

3. I currently exercise somc, but not regularly.

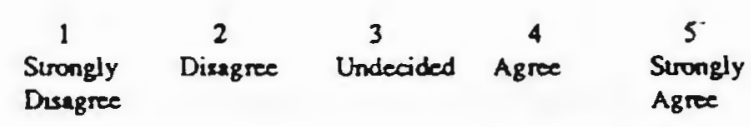

4. I currently excrcise regularly, but I have only begun doing so within the last 6 months.

\begin{tabular}{|c|c|c|c|c|}
\hline 1 & 2 & 3 & 4 & 5 \\
\hline $\begin{array}{l}\text { Strongly } \\
\text { Drsagree }\end{array}$ & Dixagree & Undecided & Agree & $\begin{array}{l}\text { Strongly } \\
\text { Agree }\end{array}$ \\
\hline
\end{tabular}

5. I currently exercise regularly, and have done so for longer than 6 months.

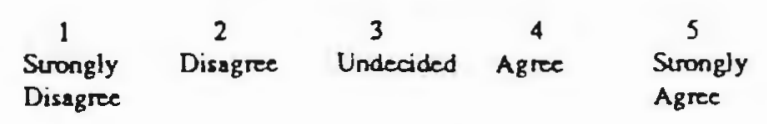

6. I have excrcised regularly in the past, but I am not doing so currenuly.

$\begin{array}{ccccc}1 . & 2 & 3 & 4 & 5 \\ \text { Surongly } & \text { Disagree } & \text { Undecided } & \text { Agree } & \begin{array}{c}\text { Strongly } \\ \text { Disagree }\end{array}\end{array}$




\section{APPENDIX D THE PEXSCPO}

Please circle the number that best represents your answer. (Regular exercise $=3$ times or more per week for fifteen minutes or longer.)

Questions 1 - 5 describe how a person might feel about his or her exercise status. Please indicate the extent to which you tend to agree or disagree with each statement. In each case, make your choice in terms of how you feel right now, not what you have felt in the past or would like to feel.

1. I currently do not exercise and I do not intend to start exercising in the next 6 months.

\begin{tabular}{|c|c|c|c|}
\hline 1 & 2 & 3 & 4 \\
\hline $\begin{array}{l}\text { Surongly } \\
\text { Disagree }\end{array}$ & Disagree & Undecided & Agree \\
\hline
\end{tabular}

2. I currently do not exercise, but I am thinking about starting to exercise in the next 6 months.

\begin{tabular}{|c|c|c|c|c|}
\hline 1 & 2 & 3 & 4 & 5 \\
\hline $\begin{array}{l}\text { Strongly } \\
\text { Disagree }\end{array}$ & Disagree & Undecided & Agree & $\begin{array}{l}\text { Strongly } \\
\text { Agree }\end{array}$ \\
\hline
\end{tabular}

3. I currently exercise some, but not regularly.

$\begin{array}{ccccc}1 & 2 & 3 & 4 & 5 \\ \text { Surongly } & \text { Disagree } & \text { Undecided } & \text { Agree } & \begin{array}{l}\text { Surongly } \\ \text { Disagree }\end{array}\end{array}$

4. I currently exercise regularly.

\begin{tabular}{|c|c|c|c|c|}
\hline 1 & 2 & 3 & 4 & 5 \\
\hline $\begin{array}{l}\text { Surongly } \\
\text { Disagree }\end{array}$ & Disagree & Undecided & Agree & $\begin{array}{l}\text { Surongly } \\
\text { Agree }\end{array}$ \\
\hline
\end{tabular}

5. I have exercised regularly in the past, but I am not doing so currently.

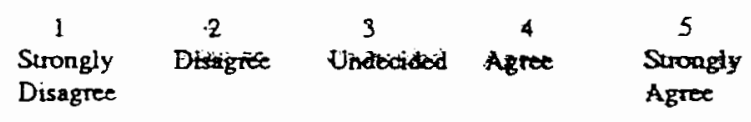




\section{Part I}

Exarcise includes activities such as brisk walking, jogging, swimming, acrobic dancing, biking, rou.ing, ct A.uvilies that are primarily sedentary, such as hi)wling or plaving golf with a goll cart, would not be consi exiscise. Plivase read the following stutements and circle True or Falsi to ill items.

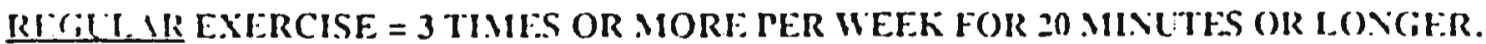

1. I currenuly do not cxcreise.

1. True 2. Fulse

2. I intend to exereise in the next 6 months.

1. True 2. Falso

3. I currinlly exercise revulurls:

1. True 2. Falsc

†. I have excreised readiur!y for the past 6 months.

1. Trus 2. Fallx

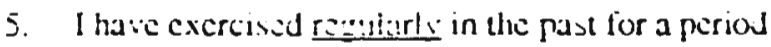
ot at least 3 montris.

1. Trui 2. Falio

\section{STAGES SCORIIIG ALGORITHM--EYERCISE}

if question $1=1$ and question $2=2$ then STASE = Precontemplation

if question $1=1$ and question $2=1$ then SIAGE = Contenplation

if question $1=2$ and question $3=2$ then STAGE = Prenaration

if question $3=1$ then STAGE = Action

if question $3=1$ and question $4=1$ then STAGE = : 9 iatenance 


\section{PLEASE COMPLETE OTHER SIDE FIRST}

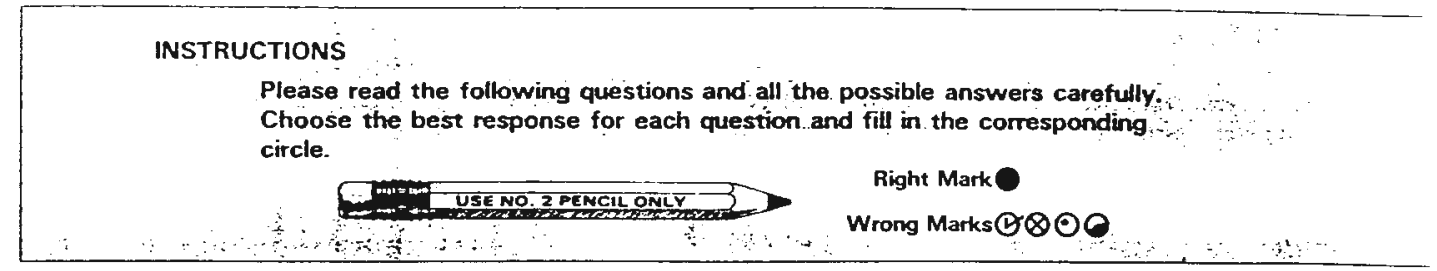

1. Do you consistently use seatbelts as a driver or passenger in a car?

OYES. I have been for MORE than 6 months.

OYES. I have been. but for LESS than 6 months

ONO. but 1 intend to in the next 30 days.

ONO, but 1 intend io in the next 6 months

ONO. and i do NOT intend to in the next 6 months

2. Do you consistently avoid eating high fat foods? OYES. I have been for MORE than 6 months.

OYES, have heen. but for LESS than 6 months

ONO. but 1 mrend to in the rext 30 days

ONO. but I mend to in the next 6 montlis

ONO and 1 do NOT mend to $n$ the nex: 6 mont ss

3. Have you been eating a diet high in fiber? OrES have betan fOI MORE than 6 monthe Y YES. I have been. bu for LESS than 6 months Oivo but inethd wo th the lexi 30 days. Oiva nu miend to whe hey 6 months ONO. and 1 do NOT miend io in the next 6 montus

4. Have you been trying to lose weight? OYES. I have been for MORE than 6 months OYES. I have been. but for LESS than 6 nouth ONO. but : mtend to in the rexi 30 days ONO. but t iritend to in the next 6 nomits

NO, and I do NOI mend to in the next 6 months

5. Do you exercise three times a week for at least 20 minutes each time?

OYES I have been fur MORE than E munths

OYES. I have heen. hut for LESS than 6 mionths

ONO. hut 1 mtend to in the next 30 days

ONO. but 1 intend to in the next 6 inonths

ONO. and 1 do NOT untend 10 w the next 6 months.
6. Do you take precautions against exposure to the sun? OYES. I have been for MORE than 6 months.

OYES. I have been. but for LESS than 6 months

ONO. but 1 intend to in the next 30 days

ONO. but $I$ interd to in the rext 6 months

ONO. and 1 do NOT intend to in the nexi 6 nuonths

7. Do you consistently use sunscreens when in the sun for more than 15 minutes?

OYES. 1 have been for MORE than 6 months

OYES, 1 have been, but for LESS than 6 months

ONO. but 1 intenci to $n$ the next 30 days.

ONO. but 1 intenct to in the next 6 months

ONO and 1 do NOT watend to m ihe next 6 moritis

8. Have you attempted to reduce the amount of stress in your daily life?

OYES. I have betn for MORE than 6 months

Ores. : have herer bu to: LESS than 6 nom

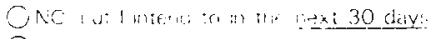

ONO but thend to in the rexi 6 montis

ONO. and 1 do NOI Hated on in the iext 6 nrma

9. Have you quit smoking cigarettes?

Y YES. 1 quI MORE han 6 months dqu

OYCS 1 qui LESS than 6 'mntius anO

ONO but 1 arfori a qut m ine nexi 30 dus

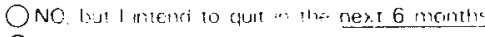

ONO and do NOI waend in quit in the nexi 6 mants

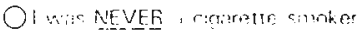

10. Do you examine yourself for warning signs of cancer (for example, breast. testicles. skin)?

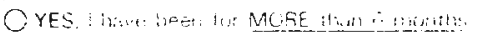

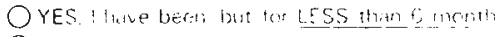

ONO but l and we wh the

ONO. but 1 menc: wo the nex: 6 montix.

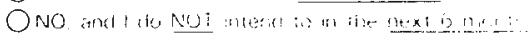

\section{FOR WOMEN ONLY}

11. Have you had a mammogram in the past 12 months? ....... O Y $\mathrm{s}$

12. Do you intend to have a mammogram in the next 12 months?. $\bigcirc$ ys:

13. Have you had a pap smear in the past 12 months? .......... Y Yes

14. Do you intend to have a páp smear in the next 12 months?... Oy-s 


\section{Bibliography}

Anderson, T. W., \& Rubin, H. (1956). Statistical inference in Factor Analysis. Proceedings of the Third Berkeley Symposium on Mathematical Statistics and Probability, 5, $111-150$.

Bandura, A. (1977). Self-Efficacy: Toward unifying theory of behavioral change. Psychological Review, $\underline{84}$ $191-215$.

Bentler, P.M. (1989). EOS: Structural equations program manual. Los Angeles, CA: BMDP Statistical Software. Bentler, P.M. (1990). Comparative fit indexes in structural models. Psychological Bulletin, 107, 238-246.

Biener, L. \& Abrams, D.A. (1991). The Contemplation Ladder: Validation of a measure of readiness to consider smoking cessation. Health Psychology, 10, 360-365.

Bollen, K.A. (1989). Structural equations with latent variables. New York: John-Wiley \& Sons.

Byrne, B.M., A Primer of LISREL: Basic applications and programming for Confirmatory Factor Analytic Models. New York: Springer Verlag.

Cronbach, L.J. (1951). Coefficient alpha and the internal structure of tests. Psychometrika, 16, 297-334. DiClemente, C.C. \& Hughes, S.O. (1990). Stages of change profiles in outpatient alcoholism treatment. Journal of Substance Abuse, 2 , 217-235.

Dishman, R.K. (Ed.). (1988). Exercise Adherence: Its impact on public health. Champaign, IL: Human Kinetics 
Books.

Hayduk, L.A. (1987). Structural equation modeling with LISREL: Essentials and Advances. Baltimore: Johns Hopkins University Press.

Horn, J.L. (1965). A rationale and test for the number of factors in factor analysis. Psychometrika, 30, 179185.

Janis, I.L. \& Mann, L. (1977). Decision Making: A

Psychological Analysis of Conflict, Choice and Commitment. New York:

Collier Macmillan.

Joreskog, K.G., \& Sorbom, D. (1986). PRELIS A program for multivariate data screening and data summarization: A preprocessor for LISREL. Mooresville, IN: Scientific Software, Inc.

Joreskog, K.G., \& Sorbom, D. (1979). Advances in factor analysis and structural equation models. Cambridge, MA.: Abt Books.

Joreskog, K.G., \& Sorbom, D. (1990). LISREL VII: Analysis of Linear Structural Relationships by the Method of Maximum Likelihood (User's Guide). Mooresville, IN: Scientific software, Inc.

Joreskog, K.G. \& Sorbom, D. (1989). LISREL VI user's guide. Mooresville, IN: Scientific Software. Kaplan, D. (1989). Model modification in covariance structure analysis: Application of the expected parameter change statistic. Multivariate Behavioral 
$\underline{\text { Research }}, \underline{24}, 285-305$.

Kerlinger, F.N. \& Pedhazur, E.J. (1973). Multiple Regression in Behavioral Research. New York: Holt, Rinehart and Winston.

Kohlberg, L. (1976). Moral stage and moralization: The cognitive developmental approach. In T. Lickona (Ed.). Moral development and behavior: Theory, research and social issues. New York: Holt, Rinehart \& Winston. Lautenschlager, G.J. (1989). A comparison of alternatives to conducting Monte Carlo analyses for determining parallel analysis criteria. Multivariate Behavioral $\underline{\text { Research, }} \underline{24}, 365-395$.

MacCallum, R.C. (1986). Specification searches in covariance structure modeling. Psychological Bulletin, 100, $107-120$.

Marcus, B.H. Emmons, K.M., Abrams, D. B. Marshall, R. Kane, M. , Etzel, R. A., \& Novotony, T. (1992). Biological Feedback as part of a worksite smoking cessation program: Impact on smokers and non-smokers. Manuscript in preparation.

Marcus, B.H., Selby, V.C., Niaura, R.S., \& Rossi, J.S. (1992). Self-Efficacy and the stages of exercise behavior change. Research Quarterly for Exercise and Sport, $\underline{63}, 60-66$

Marcus, B.H., Rossi, J.S., Selby, V.C., Niaura, R.S., \& Abrams, D.B. (1992). The stages and processes of exercise adoption and maintenance in a worksite sample. 
Health Psychology, 11, 386-395.

McConnaughy, E.A., Prochaska, J.O., \& Velicer, W. F. (1983).

Stages of change in psychotherapy: measurement and

sample profiles. Psychotherapy: Theory, Research, and

Practice, 20, 368-375.

McConnaughy, E.A., DiClemente, C.C., Prochaska, J.O., \&

Velicer, W.F. (1989). Stages of Change in

Psychotherapy: A Follow Up Report. Psychotherapy, 26, $494-503$.

Mulaik, S.A., James, L.R., Van Alstine, J., Bennett, N.,

Lind, S., \& Stilwell, C.D. (1989). Evaluation of

goodness-of-fit indices for structural equation models.

Psychological Bulletin, 105, 430-445.

Norusis, M.J. (1990). SPSS Introductory Statistical student

Guide Chicago: SPSS, Inc. (pp 309-320).

Piaget, J. (1960). The child's conception of the world.

Totowa, NJ: Littlefield Adams.

Piaget, J. (1972). Intellectual evolution from adolescence

to adulthood. Human Development, 15, 1-12.

Prochaska, J.O. (1984). Systems of Psychotherapy: A

transtheoretical analyses (2nd edition). Homewood, IL:

The Dorsey Press.

Prochaska, J.O. \& DiClemente, C.C. (1983). Stages and

processes of self change of smoking: toward and

integrative model of change. Journal of Consulting and

Clinical Psychology, 51, 390-395.

Prochaska, J.O. \& DiClemente, C.C. (1985). Common processes 
of change in smoking, weight control and psychological distress. In S. Shiffman and T. Wills (Eds.) Coping and Substance Use: A Conceptual Framework. New York: Academic Press.

Prochaska, J.O. \& DiClemente, C.C. (1986). Toward a comprehensive model of change. In W.R. Miller and N. Heathers (Eds.), Treating Addictive Behaviors, (pp 3 -27). New York: Plenum.

Prochaska, J.O., DiClemente, C.C., Velicer, W.F., Ginpil, S., \& Norcross, J.C. (1985). Predicting change in smoking status for self changers. Addictive Behavior, 10, $395-406$.

Prochaska, J.O., Velicer, W.F., DiClemente, C.C., \& Fava, J. (1988). Measuring processes of change: Application to the cessation of smoking. Journal of Consulting and Clinical Psychology, 56, 520-528.

Prochaska, J.O., Velicer, W.F., Guadagnoli, E., Rossi, J.S., \& DiClemente, C.C. (1991). Patterns of change: Dynamic typology applied to smoking cessation. Multivariate Behavioral Research, 26, 83-107.

Prochaska, J.O., Velicer, W.F., Rossi,.J.S., Goldstein, M.G., Marcus, B.H., Rakowski, W., Fiore, C., Harlow, L.I., Redding, C.A., Rosenbloom, D., \& Rossi, S.R. (in press). Stages of change and decisional balance for twelve problem behaviors. Health Psychology, Silva, E.S., \& MacCallum, R.C. (1986). Some factors affecting the success of, specification searches in 
covariance structure modeling. Multivariate Behavior Research, 23, 297-326.

Sonstroem, R.J. (1988). Psychological Models. In R. K.

Dishman (Ed.). Exercise Adherence: Its Impact on Public Health (pp. 125-153). Champaign, IL: Human Kinetics Books .

Stern, R.A., Prochaska, J.O., Velicer, W.F., \& Elder, J.P. (1987). Stages of adolescent cigarette smoking acquisition: Measurement and sample profiles. Addictive Behaviors, 12, 319-329.

Stephens, T., Jacobs, D.R., Jr., \& White, C.C. (1985). A descriptive epidemiology of leisure-time physical activity. Public Health Reports, 100, 147-158. Velicer, W.F. (1976). Determining the number of components from the matrix of partial correlations. Psychometrika, $\underline{41},, 321-337$.

Velicer, W.F., DiClemente, C.C., Prochaska, J.O., \& Brandenburg, N. (1985). A decisional balance measure for assessing and predicting smoking status. Journal of Personality and Social Psychology, 48, 1279-1289. Velicer, W.F., DiClemente, C.C., Rossi, J.S., \& Prochaska, J.O. (1990). Relapse situations and self-efficacy: An integrative model. Addictive Behaviors, 15. 271-283. Velicer, W.F., Fava, J.L., Harrop, J.W., \& Zwick, W.R. (1991), Component Analysis Extended (CAX) computer program. Unpublished computer program, University of Rhode Island. 
Velicer, W.F., Prochaska, J.O., Rossi, J.S., \& Snow, M.

(1992). Assessing Outcome in Smoking Cessation studies Psychological Bulletin, 111, 23-41.

Velicer, W.F., Rossi, J.S., Prochaska, J.O., \& DiClemente, C.C., (1992). A Criterion Measurement Model for Addictive Behavior. Psychological Review submitted for review.

Ward, J. (1963). Hierarchical grouping to optimize an objective function. Journal of the American statistical Association 58, 236-244. 